VITÁRI Zsolt

DOI: 10.15170/DIKE.2019.03.02.09

Lehrstuhlleiter, Dr. habil.

Universität Pécs, Lehrstuhl für Zeitgeschichte

\title{
Minderheitenrecht in Ungarn in der Zwischenkriegszeit und dessen Anwendung im Alltag am Beispiel der Ungarndeutschen ${ }^{1}$
}

\section{Minority Rights in Hungary in the Interwar Period and their Application through the Example of the Everyday Life of the Hungarian Germans}

After 1920, a new stage began in terms of the endeavours for the ethnic homogenisation in Hungary. The most important obstacle of this was that in consequence of the delamination of the new frontiers of the country, the Germans, who formed a large ethnic minority were not able to find a way towards building their own groups and their selforganization. By means of the international organizations for the protection of minorities this would have been improved, but Hungary made efforts to prevent the German from finding their ethnic revival by bureaucratic means. The majority of these tools were the further developed versions of those employed before 1918. The powerful supervision, the inflaming popular feeling regarding the pan-German danger, prevention of their activity in the field of self-organization, the military enforcement of the law, operations of the police and gendarmerie, advertisements, arrests and violence formed a well-functioning system. Through this system, the international guaranteed rights of ethnic groups could have been sabotaged.

Keywords: Germans in Hungary, ethnic homogenising, minority rights, group-building, sabotaging minority rights

\section{Einleitung}

Seit dem österreichisch-ungarischen Ausgleich 1867 etablierte sich Ungarn zu einem modernen Rechtsstaat. Ein Umstand, der naturgemäß auch auf die unterschiedlichen Subgruppen der Gesellschaft auswirkte, so auch auf die ethnischen und religiösen Minderheiten des Landes. Während es infolge der Nation Buildings-Prozesse sowie der sich vermehrenden ethnischen Konflikte immer mehr zum europäischen Maßstab wurde, solche Gruppen zu schützen, kollidierte dies immer mehr mit dem Wunsch auf Einrichtung von möglichst homogenen Nationalstaaten, in denen diese Art von Schutz gar nicht nötig sei.

Ungarn bedeutet insofern ein Sonderfall, dass es Mitte des 19. Jahrhunderts den größten Anteil an nicht ungarischen Bevölkerungsteilen auswies, während der Anteil der Ungarn - zwar als

\footnotetext{
${ }^{1}$ Der Aufsatz ist die redigierte Version des gleichnamigen Vortrags, gehalten im Rahmen der wissenschaftlichen Tagung „Theorie und Praxis der Entrechtung in der zweiten Hälfte der Hortby-Ära im Vergleich mit dem NS-Regime” (Pécs, 2.-6. September 2019).
} 
größte ethnische Gruppe des Landes und Titularnation - nicht mal 40 \% erreichte. Indem anfangs dieser Situation durch die Anwendung der Staatsnationskonzeption gerecht wurde, begann die ungarische Politik seit Mitte der 1870er Jahre immer mehr zu der Kulturnation zu übergehen, das jedoch mit der Wahrung der territorialen Integrität des Landes. Demnach wurde eine ethnische Absonderung immer weniger toleriert. Da die natürliche Assimilation als zu langsam erachtet wurde, folgten Gesetze (insbesondere im Schulwesen), ${ }^{2}$ die die ethnische Homogenisierung des Landes beschleunigen sollten. Durch diese wurden insbesondere die sprachnationalistischen Tendenzen bekräftigt.

Der wesentlichste Charakterzug des ethnopolitischen Systems wurde, dass die Homogenisierung streng von der Verwaltung überwacht und vorangetrieben wurde, wobei sie die Ausübung der durch Gesetze oder sonstige Regelungen zugesprochene Rechte zu hindern oder mit administrativen Mitteln unmöglich zu machen wusste.

\section{Genese der bürokratischen Überwachung der Nationalitäten vor 1918}

Im Sinne der Homogenisierungsbestrebungen wurden ab den 1870er Jahren immer mehr Gesetze und Verordnungen für die Überwachung der Nationalitätenorganisationen herausgegeben, die das größte Hindernis bei der ethnischen Vereinheitlichung darstellten. Gemäß dem Gesetzesartikel 44 aus dem Jahr 1864 hatte ein Staatsbürger gleich welcher Nationalität nämlich das Recht, ,sich außer in Einrichtungen, die der Förderung von Sprache, Wissenschaft, Wirtschaft, Industrie und Handel dienen, unter der gesetzlichen Aufsicht des Staates auch in Vereinigungen oder Vereinen zusammenzuschließen ". ${ }^{3}$ Das Nationalitätengesetz von 1868 garantierte den Nationalitäten außer dem Sprachgebrauch in der örtlichen Verwaltung und im kirchlichen Leben und der muttersprachlichen Schulausbildung in den Volksschulen, ebenfalls die Vereinigungsfreiheit.

Doch bereits der Runderlass des Innenministers Nr. 1394 aus dem Jahr 1873 knüpfte die Betätigung der Vereine an eine ministerielle Genehmigung. Ab 1874 wurde es Pflicht, dass die grundlegenden Daten der Vereine von jedem Munizipium in einem Vereinsbuch registriert wurden. Die Vereine, die ihre Satzung oder ein Gesetz verletzten, konnten von den Munizipien aufgelöst werden. ${ }^{4}$ Ab 1875 wurde die Kontrolle weiter verschärft: Die Nationalitäten durften von da an nur noch kulturelle und literarische Vereine gründen, keine politischen $m e h .^{5}$ Es ist also kein Zufall, dass insgesamt nur fünf Prozent der Vereine nicht-ungarisch waren, und ein Drittel der Vereine explizit den ungarischen nationalen Charakter betonte. ${ }^{6}$ Abgesehen von einigen Ausnahmen war die Gründung von landesweiten Organisationen, die über die lokale oder regionale Ebene hinausreichten, nicht kennzeichnend. ${ }^{7}$

\footnotetext{
2 Das Volksschulgesetz von 1879 machte die ungarische Sprache zum Pflichtfach an allen Volksschulen des Landes. Das Mittelschulgesetz von 1883 verordnete Ähnliches an Gymnasien und Realschulen. 1891 folgten die Kindergärten, in denen die Erzieherinnen verpflichtet wurden, die Kinder mit der ungarischen Sprache vertraut zu machen. 1907 erreichte die Magyarisierung ihren Höhepunkt mit dem berüchtigten lex Apponyi, das vorschrieb, dass jede Kind in Ungarn bis zum Ende der vierten Klasse des Ungarischen in Wort und Schrift mächtig sein sollte.

${ }^{3}$ MÓRÓ, Olvasóegyletek és népkönyvtárak Baranyában 169.

${ }^{4}$ MÓRÓ, Olvasóegyletek és népkönyvtárak Baranyában 169.

${ }^{5}$ BŐZSE, „Az egyesületi élet a polgári szabadság ..." 17-20.

${ }^{6}$ REISZ, Egyletek a dualizmuskori Magyarországon 940-941.

${ }^{7}$ MANNOVÁ, Das Vereinswesen in Ungarn und die Revolution 60.
} 
Das Gesetz Nr. V. des Jahres 1878 führte den Tatbestand der „Aufwiegelung gegen Nationalitäten "ein. Danach sollten Personen, die in Wort, Schrift oder Bild zum Hass aufhetzten, zu Zuchthaus und Geldstrafe verurteilt werden können. ${ }^{8}$ Die Anwendung des Gesetzes zeigte aber, dass es in erster Linie dem „Schutz“ der ungarischen Nationalität diente. Damit wurde der Öffentlichkeit nach und nach vermittelt, welche „Gefahr“ der Panslawismus und Pangermanismus bedeuteten.

Vermutlich führte die weiterhin steigende Zahl an Vereinen und die Erstarkung der magyarisierenden Absichten dazu, dass die Verordnung des Innenministeriums Nr. 1136 aus dem Jahr 1898 eine Tätigkeit ohne Satzung oder die Abweichung von ihr bereits mit einer Geldstrafe beziehungsweise mit Haft sanktionierte.

$\mathrm{Ab}$ den 1890er Jahren wurden die Lehraufsichten durch mehrere Verordnungen darauf aufmerksam gemacht, die Schulabgänger mit der Organisation von Jugendvereinen zusammenzuhalten, und sie wurden dazu angehalten, insbesondere in den nicht-ungarischen Gebieten die nicht-ungarischen Jugendlichen dazu zu bewegen, in ungarische Jugendvereine einzutreten. ${ }^{10}$ Damit sollte vermieden werden, dass der magyarisierende Einfluss mit dem Verlassen der Schule abebbte. Trotz allem hat es den Anschein, als hätte man das gewünschte Ergebnis innerhalb eines Jahrzehnts nicht erreicht, da zu Beginn des 20. Jahrhunderts das Ministerium für Kultus und Unterricht landesweit neuen Schwung in die Sache brachte und sich verstärkt auch die Verwaltungsorgane zur Hilfe holte. Der Erfolg ließ sich sehen: in Regionen mit einem hohen Nationalitätenanteil entstanden 620 solcher Vereine. Damit erfüllten 3,7 \% aller Schulen und 21$22 \%$ der staatlichen Schulen die Erwartungen des Ministeriums. ${ }^{11}$

In ähnlicher Form sollten die Leibeserziehung und die Waffenübungen gefördert werden. Nach vereinzelten und unzureichenden Erfolgen fand man mit der Gründung des Landesrates für Leibeserziehung (Országos Testnevelési Tanács, OTT) die endgültige Form, um die entsprechenden Grundlagen zu schaffen. Hier arbeitete man das System für die Militärausbildung der Jugend aus, ${ }^{12}$ das dann schließlich ab 1921 in Gestalt der Levente-Bewegung in die Praxis umgesetzt wurde und selbstverständlich nicht nur der Vorbereitung zum Militärdienst diente, sondern auch der Vermittlung einer christlich-nationalen Wertordnung und zugleich einer Magyarisierung.

Zur genauen Überwachung der Vereinstätigkeiten bei den nationalen Minderheiten wollte die Regierung außer mit den Regelungen durch Verordnungen und Gesetze für die Verwaltungsorgane auch damit beitragen, dass sie das Königliche Zentralamt für Statistik (Királyi Központi Statisztikai Hivatal) anwies, Landkarten und Diagramme nach Städten und Gemeinden gegliedert anzufertigen, anhand derer sich die Führungskräfte der regionalen Verwaltungseinheiten über die Nationalitätenverhältnisse und damit den Gefahrengrad der Aufwiegelung durch Nationalitäten informieren konnten. ${ }^{13}$ So bürgerte sich schon in der Zeit des Dualismus die Praxis

\footnotetext{
${ }^{8}$ GA 1878: V \ 172.

9 P. MIKLÓs, „Ifjúsági szerveződések évszázadai“ - gyermek- és ifjúsági szervezetek https://epa.oszk.hu/00000/00035/00010/1997-11-mk-P-Miklos-Ifjusagi.html

${ }^{10}$ Ebd.

${ }^{11}$ Ebd.

12 Ebd.

13 „Zur erfolgreichen Ausübung der unter dem Gesichtspunkt der ungarischen nationalen Interessen notwendigen ständigen Wachsamkeit
} 
ein, dass die Genehmigung eines Vereins bis zu zwei Jahre in Anspruch nehmen konnte, da die Zuverlässigkeit der Organisationen vom gesamten Verwaltungsapparat überprüft wurde.

Das Instrumentarium an Sanktionen, das zur Verfügung stand, wurde, falls notwendig, auch gegen die Jugendvereine eingesetzt. Am 24. August 1914 entzog der Innenminister dem Budapester serbischen Jugendzirkel Kola Mladik Szrba die Genehmigung und ähnlich ging man später auch gegen einen Verein in Lórév vor. Schon als man die Erteilung der Genehmigung abwog, bat der Obergespan des Komitats Pest den Vizegespan herauszufinden, ob „die Personen, die diesen Verein gründen, ausreichend Zuverlässigkeit gewährleisten, damit dieser Verein nicht die nationale Tenden₹ verstärkt und so eine notwendige Magyarisierung verbindert" ${ }^{14}$

Daher suchten die Nationalitäten bei der Gründung ihrer Vereine nach kreativen Ansätzen, um weniger in den Fokus der Behörden zu gelangen. Schon bei der Vorlage ihrer Satzung versuchten sie, ihre tatsächlichen Ziele zu verheimlichen, so beispielsweise der Pomázer Bestattungsverein St. Georg (Pomázi Szt. György Temetkezési Egyesület), der weder sprachliche noch konfessionelle Bedingungen an seine Mitglieder stellte, obwohl grundlegend die Pflege der serbischen Identität Sinn und Zweck des Vereins war. ${ }^{15}$

Die Gründung von Nationalitätenorganisationen war für die Deutschen in Ungarn vor dem Ersten Weltkrieg nicht sonderlich kennzeichnend. So gab es beispielsweise in dem vielfältigen Vereinsleben und unter den Vereinen in Pressburg, wo lange Zeit eine deutsche Dominanz vorherrschte und die Magyarisierung erst später einsetzte, trotz des Gebrauchs des Deutschen als offizielle Sprache des Vereins (der Wechsel zum Ungarischen erfolgte später) bis 1918 keinen Verein, der sich im ethnischen Sinne als deutscher Verein betrachtet hätte, auch in den Namen der Vereine wurde das Adjektiv „deutsch“ nicht verwendet. Das heißt, die Grundlage für eine bürgerliche Vereinigung und das gesellige Beisammensein war in Pressburg nicht die Ethnizität, was sich darauf zurückführen lässt, dass das Bürgertum sich aufgrund seiner Loyalität und mehrfachen Bindung nicht entscheiden konnte und wollte; man hielt die ethnische Frage überhaupt nicht für wichtig, sondern betrachtete eine solche Entscheidung eher als milieufremd. Vermutlich verhielt sich das in den übrigen Städten ebenso. Viel stärker als ihre deutsche Ethnizität manifestierten die Deutschen ihren ungarischen Patriotismus, bei den Volkszählungen bezeichneten sie sich zunehmend als Ungarn, und auch in den Familien ging ein Sprachwechsel vonstatten. ${ }^{16}$

In der Umgebung von Budapest diente das rege Vereinsleben ebenfalls dazu, die

und Funktion sollen leicht überschaubare Hilfsmittel zur Verfügung stehen. "Der Innenminister erwartete von Obergespanen jedoch besondere Umsicht: „Ich fordere Eure Exzellenz auf, die Landkartenseiten in den eigenen offiziellen Räumen sorgfältig ₹u verschließen und wie vertrauliche Schriftstücke zu handhaben, damit ibre Angaben nicht an die Öffentlichkeit gelangen und so eventuell die Wortfübrer der Nationalitäten von ibnen Kenntnis bekommen, denn damit würden die Betreffenden im Hinblick auf die Angaben auf anschauliche und leicht überschaubare Weise an Informationen kommen, an die sie derzeit nicht leicht gelangen, andererseits würden wir mit der Veröffentlichung der Angaben der Landkarten den Nationalitäten eine Waffe zu ibrer Verteidigung in die Hand geben und vielleicht das notwendige Instrument, um regelmäßige Aktionen in Gang zu setzen. "Zitiert von SEBESTYÉN, Szerb egyesületek és nemzetiségi politika 89.

14 Zitiert von SEBESTYÉN, Szerb egyesületek és nemzetiségi politika 94.

15 Zitiert von SEBESTYÉN, Szerb egyesületek és nemzetiségi politika 91.

16 MannOVÁ, Identitätsbildung der Deutschen in Pressburg im 19. Jahrhundert 60-76, 64, 75-76. Siehe das Beispiel der Familie Angster aus Pécs, METZ, Josef Angster. Das Tagebuch eines Orgelbauers 23, oder etwa die Familie von Sándor Márai, MÁRAI, Bekenntnisse eines Bürgers, Erster Teil, Kapitel 3. 
Magyarisierung unter Beweis zu stellen. ${ }^{17}$ Durch die intensive Magyarisierung des deutschen Bürgertums verloren die Ungarndeutschen ihre obere soziale Schicht - was unter den Nationalitäten eine einzigartige Erscheinung war $-{ }^{18}$ und das hemmte wiederum stark die Entstehung einer ethnisch gefärbten Vereinskultur.

Auf dem Land war ein ähnliches Phänomen zu beobachten, da sich die obere bäuerliche Schicht als Teil der Elite betrachtete und zur Elite des Landes gehören wollte, die im ethnischen Sinne als ungarisch galt. ${ }^{19}$ Dieser Umstand erklärt, warum sich die Personen, die eine ethnische Bewegung hätten anführen können, davon distanzierten; sie vermieden es, sich zu ihrer Ethnizität zu bekennen, die unteren Schichten aber zeigten weniger Interesse, sich zu organisieren.

Hinzu kam, dass die jungen Deutschen, die aus der Provinz in die Reihen der Intelligenz aufstiegen, nach dem Verlassen der Volksschule - wenn diese nicht schon bereits eine ungarische gewesen war - in den höheren Schulen sowie an den Hochschulen dem Einfluss der ungarischen nationalen Erziehung nicht mehr entgehen konnten, egal, ob sie eine kirchliche oder staatliche Lehreinrichtung besuchten. Die auf diese Weise aufsteigende Schicht, deren Mitglieder in vielen Fällen an ihren Heimatort zurückkehrten, konnte somit ebenfalls kein Träger einer ethnisch basierten Bewegung sein. ${ }^{20}$

Auch in den Gemeinden der Agrarregionen wurden der Reihe nach Organisationen gegründet. Laut den Forschungen von Attila Márfi entstanden im Komitat Baranya - einem der wichtigsten Siedlungsgebiete der Deutschen - nach 1867 in etwas weniger als der Hälfte der Gemeinden 800 Vereine. Von diesen besaßen insgesamt nur dreißig einen Nationalitätencharakter und zwölf von ihnen waren deutsch: zehn katholische Lesezirkel, ein Gesangsverein und ein Kasinoverein in Pécs. Um die Jahrhundertwende gab es in den drei Komitaten der Schwäbischen Türkei 400 von Deutschen bewohnte Gemeinden, in denen irgendeine Art von Verein existierte, was bedeutet, dass 19 Prozent der erwachsenen deutschen Bevölkerung gesellschaftlich aktiv war. Da diese Vereine jedoch in erster Linie religiöse und kulturelle beziehungsweise wirtschaftliche Vereine oder Selbsthilfevereine (Bestattungsvereine, Feuerwehr usw.) darstellten, ,waren sie als Mittel zurpolitischen Mobilisierung, der gesellschaftlichen Modernisierung und/ oder der nationalen Eman₹ipation nur in beschränktem Maße effektiv".21 Sie waren vor allem ein Mittel zum Erhalt der traditionellen Ordnung.

Eine abweichende Vereinskultur war nur in Siebenbürgen $\mathrm{zu}$ beobachten, was dort

\footnotetext{
17 Vgl. SOMLAI, A magyarországi németség története 35.

18 HUTTERER, Die deutsche Volksgruppe in Ungarn 293.

${ }^{19}$ Ferenc Herczeg beschreibt dies anschaulich: „Damals meinte man in Südungarn, das einer nur bis fünfhundert Morgen Raize oder Schwabe sein kann, darüber hinaus muss er Magyare sein, wenn er ein Leben, das seines Vermögens würdig ist, fübren will". NÉMETH, Herczeg Ferenc emlékezései 85.

${ }^{20}$ „Unsere Seelen wurden 8 Jahre hindurch mit madjarischen Kulturgütern ernäbrt. Alles, was unsere für das Gute und Schöne empfänglichen jugendlichen Gemüter ergötzte und ergriff, war uns in madjarischem Gewande entgegengetreten. Die schönen madjarischen Lieder, die ergreifenden madjarischen Gedichte, die Literatur und die in ibr gepriesenen Landschaften atmeten madjarischen Geist. Im Geschichtsunterricht wurden uns die großen Gestalten und Taten des madjarischen Volkes vor Augen gefübrt. Die madjarischen Dichter, Redner, Staatsmänner, Helden wurden unsere Ideale. Die Herrlichkeit des madjarischen Volkes, das uns als das erste, das edelste Volk der Welt geschildert wurde, hatte uns in ibren Bann geschlagen. Wir waren stolz, daß man auch uns zu diesem Volke zählte. [...] Wir börten dagegen viel darüber, daß die Deutschen mit den Madjaren oft Krieg geführt und immer wieder versucht hatten, sie zu unterdrücken, daß die Madjaren aber immer Sieger geblieben seien. Die Deutschen waren für uns Feinde des edlen madjarischen Volkes. "WIESER, Wir zogen aus Schwaben nach Osten 41.

${ }^{21}$ MÁRFI, Baranya nemzetiségi egyesületei a dualizmus idején 9; SzITA, Adatok a Magyarországi Németek Országos Gazdaszövetsége történetéhez 244; GOTTAS, Vereine, Parteien und Interessenverbände der ungarländischen Deutschen 1205.
} 
maßgeblich auf die religiöse Sonderstellung zurückzuführen war. Dort fand man das gesamte Spektrum des Vereinslebens vor, in dem wirtschaftliche und kulturelle Vereinigungen ebenso präsent waren wie Frauen- oder Turnvereine, die zu einem Großteil in der zweiten Hälfte des 19. Jahrhunderts entstanden. ${ }^{22}$ Eine ebenfalls abweichende Entwicklung war im Banat zu erkennen. Infolge der langen Autonomie, die die Region zur Mitte des 19. Jahrhunderts, zwischen 1849 und 1860, erneut erlangte, bildete sich hier ein Bürgertum heraus, das sich an Wien orientierte und eine Vielzahl an deutschsprachigen Vereinen, Zeitungen und kulturellen Einrichtungen ins Leben rief. Es entstand ein Netzwerk, in dem die wirtschaftlichen Akteure, die Intellektuellen und die Agrarbevölkerung gleichermaßen ihren Platz fanden und sich einander gegenüber aufgeschlossen zeigten. Daher ist es auch kein Zufall, dass, nachdem die Autonomie des Banatgebiets aberkannt worden war, mit der Politisierung der Deutschen neben Siebenbürgen vor allem hier begonnen wurde. $^{23}$

Aus alldem folgt, dass sich bei den Ungarndeutschen - sieht man einmal von den Siebenbürger Sachsen ab - einerseits die Grundlagen der gesellschaftlichen Eigenorganisation, andererseits die Keime der Politisierung mit Blick auf die wirtschaftlichen Aspekte am ehesten im Banat und von dort ausgehend in geringerem Maße in der Batschka zeigten, wobei der ethnische Faktor, sowohl aus innerer Veranlassung als auch von außen suggeriert, zuweilen schon eine Rolle spielte. Grundvoraussetzungen waren das wirtschaftliche Potenzial, die entsprechende soziale Schichtung, die in Siebenbürgen stärkere, im Banat schwächere gesellschaftliche Mobilität und damit die Entstehung einer gebildeten gesellschaftlichen Führungsschicht, wobei es in Siebenbürgen eher darum ging, diese Schicht zu erhalten. ${ }^{24}$ Dieses Niveau erreichten andere deutsche Gebiete im Land nicht, in der Schwäbischen Türkei löste allein der Schutz wirtschaftlicher Interessen eine Reaktion in Form einer Selbstorganisation („Bauernverband“) aus, doch darüber hinaus gingen die Aktivitäten vor dem Ersten Weltkrieg nicht.

\section{Homogenisierung vs. Gruppenbildung nach 1918}

Das Jahrzehnte lang geförderte, gegarte, gut praktizierte System der Überwachung, in dem über mehrere Generationen hinweg die Mitarbeiter des Verwaltungsapparates so sozialisiert wurden, dass sie jede Regung der Nationalitäten mit scharfen Augen verfolgten, gewann nach dem Ersten Weltkrieg eine noch größere Bedeutung. Im Rahmen der neuen internationalen Rechtsordnung wurde auch der Minderheitenschutz großgeschrieben und mit dem Völkerbund schuf man zugleich eine internationale Organisation zu dessen Überwachung. Auch wenn in der Praxis dieses System wenig Effizienz zeigte, legte doch mit den Minderheitsschutzverträgen und der Möglichkeit, Versäumnisse vor die internationale Gemeinschaft bringen zu können, doch eine größere Last auf

\footnotetext{
22 Beispielsweise: Siebenbürgisch-Sächsischer Landwirtschaftsverein, Siebenbürgischer Verein für Naturwissenschaften, Siebenbürgischer Gustav-Adolf-Verein, Siebenbürgischer Karpathenverein, Allgemeiner Evangelischer Frauenverein, Verband Sächsischer Turnvereine. TEUTSCH, - TEUTSCH, Geschichte der Siebenbürger Sachsen für das sächsische Volk 189; EGRY, Nemzeti védgát vagy szolíd haszonszerzés; GOTTAS, Die Deutschen in Ungarn 378.

${ }^{23}$ SeEWAnN, Geschichte der Deutschen in Ungarn 105.

${ }^{24}$ Ebd. 102-109.
} 
die nationalen Regierungen. ${ }^{25}$

Insofern wurde der alte ungarische Mechanismus der Kontrolle der Minderheiten sehr nützlich, da man mithilfe dessen zumindest dem Schein nach den internationalen Forderungen und Verpflichtungen entsprechen konnte aber doch das neue - diesen Erwartungen völlig im Gegensatz stehende - Credo bezüglich der Minderheiten nicht aufgeben musste. Nach der Revolutions- und Räterevolutionszeit und der Etablierung des Horthy-Regimes zog man aus dem Schock des Friedensvertrages von Trianon nämlich zwei Schlussfolgerungen: einmal seien für die immensen Territorial- und Bevölkerungsverluste - denen nur die Verluste der Türkei nahekamen - in erster Linie die nicht ungarischen Völker verantwortlich, die durch ihre Sezessionsbestrebungen und Einflussnahmen auf die Großmächte die Zerstörung des historischen - tausendjährigen - Ungarn herbeiführten; zum Zweiten musste ein zweites Trianon auf alle Fälle vermieden werden, indem das mittlerweile homogenste Land der Region (Anteil der Ungarn 90\%) endgültig homogenisiert werden sollte. Dies konnte nur mit Zuwiderhandlungen gegen die internationalen Verpflichtungen passieren.

Die Situation vereinfachte sich dadurch, dass von der etwa 10-prozentigen Minderheitenbevölkerung eine einzige Minderheit wirklich Stärke zeigte, nämlich die deutsche. Nicht nur, weil sie auch zahlenmäßig die stärkste war, mit 551.000 Personen und einem Anteil von 6,9\%, sondern auch wegen ihrer wirtschaftlichen Stärke, aber noch mehr, weil die Deutschen nach dem Ersten Weltkrieg endlich die Bahn der Gruppenbildung betraten, mit dem Zweck, ihre ethnische Eigenart, Sprache und Kultur bewahren zu können. Reibungen und Konfrontationen waren somit vorprogrammiert. ${ }^{26}$

Indem der im Friedensvertrag implementierte Minderheitenschutz die Gleichberechtigung aller ungarischen Staatsbürger ohne Rücksicht auf Rassen- Religions- oder sprachliche Zugehörigkeit vorschrieb, anerkannte er auch das Recht auf Erhaltung von sozialen Einrichtungen darunter Organisationen, Schulen und sonstigen Bildungsanstalten. Zugleich musste der muttersprachliche Unterricht ermöglicht werden. Damit waren gleich alle Felder abgedeckt, in denen es in der Zwischenkriegszeit zu Kollisionen kam.

Der von Germanistikprofessor Jakob Bleyer inspirierte Gruppenbildungsprozess fußte nämlich auf drei Pfeilern. Einmal hielt er einen landesweiten Kommunikationskanal für nötig, der in verständlicher Weise geschrieben, dem Lebensmilieu der Ungarndeutschen angepasst bereits ab 1921 als Sonntagsblatt in die Hände der Ungarndeutschen kam. Dieses Wochenblatt blieb bis in die Mitte der 1930er Jahre das Hauptmedium der Ungarndeutschen und funktionierte relativ frei. In der zweiten Hälfte der 1930er Jahre übernahm diese zentrale Rolle der Deutsche Volksbote, in den 1940er Jahren die Deutsche Zeitung. Als zweiter Pfeiler dienten die Volksschulen, als dritter eine landesweite Organisation. ${ }^{27}$ Zwei Felder, die kontinuierlich Probleme bereiteten und somit ständig auf der Tagesordnung blieben.

Es war nicht schwer, die Schulen zu einem Bestandteil der öffentlichen Rede zu machen, da es in diesem Zusammenhang bereits unmittelbar nach der revolutionären Periode zu neuen

\footnotetext{
${ }^{25}$ SZALAYNÉ SÁNDOR, A kisebbségvédelem jogi intézményrendszere a 20. században; EILER, Nemzeti kisebbségek és az állammal szembeni lojalitás a két világháború között 204-219.

${ }^{26}$ Az 1920. évi népszámlálás; KOVÁCS, A németek helyzete Csonka-Magyarországon a statisztika megvilágításában.

${ }^{27}$ SEEWANN, Geschichte der Deutschen in Ungarn 232-237.
} 
Problemen gekommen war. Durch das Zurückdrängen der Minderheitenschulen - ein Phänomen, das in der Zeit des Dualismus fast durchgängig zu beobachten war - und die endgültige Festlegung der Grenzen kam das Schicksal der Schulen sofort auf die Tagesordnung. Unter der lang andauernden fremden Oberhoheit war es nämlich an mehreren Orten möglich gewesen, die Schulen in deutsche Schulen umzuwandeln. Nun - nachdem entschieden war, dass die Gemeinden weiterhin unter ungarischer Oberhoheit bleiben würden - sollten diese fast unverzüglich zu ungarischen Lehreinrichtungen gemacht werden. So geschah es beispielsweise in Elek, ${ }^{28}$ wo die Schule unter rumänischer Besetzung eine deutsche war. Oder in zahlreichen Gemeinden des Komitats Baranya während der serbisch-kroatisch-slowenischen Besetzung.

Die bekannte Verordnung Nr. 4800/1923, mit der die drei Schultypen „A“, „B“ und „C“ eingeführt wurden, sorgte für eine gewisse Entspannung der Situation. ${ }^{29}$ Nach 1927 zeigte sich dann bei der Regierung eine größere Bereitschaft, die Schulen bis zum Ende des Jahrzehnts in bedeutender Zahl in gemischtsprachige Schulen des Typs B umzuwandeln, ${ }^{30}$ allerdings kam es nur in Ansätzen zur Realisierung dieser Absicht: Bis 1928 war zwar ein Fortschritt erkennbar, auf die dann jedoch eine Stagnation folgte. ${ }^{31}$ Trotz der Absicht der Regierung, in dieser Frage zu vermitteln, zeigte sich in den nicht-staatlichen Volksschulen, die die Mehrheit ausmachten, kaum eine positive Entwicklung. Bleyer versuchte, indem er Beziehungen zu den deutschen katholischen Kreisen aufnahm, Einfluss zu nehmen, jedoch ohne jeden Erfolg. Allein der Bischof von Szombathely, Graf János Mikes, ermöglichte die vollkommene Anwendung der Schulverordnung, woraufhin sich von den sieben Gemeinden des Bistums mit mehrheitlich deutscher Bevölkerung sechs für den Typ A und eine für den Typ B entschieden. ${ }^{32}$

So existierten im Schuljahr 1928/29 49 Schulen des Typs A (10,6 \%), 98 des Typs B (21,2\%) und 316 des Typs C (68,2\%), während es im Land 325 Gemeinden mit einer mehrheitlich deutschen Bevölkerung gab. In der Schwäbischen Türkei, der Hochburg der Deutschen in Ungarn, existierten 1928/29 insgesamt 12 Schulen des Typs A..$^{33}$ Auch in den Kindergärten war die Situation nicht besser: im Jahr 1929/30 waren von den 12.500 Kindergärten 13 deutschsprachig. ${ }^{34}$ Ebenso verhielt es sich mit den mittleren und höheren Schulen, die in der Minderheitensprache praktisch gar nicht existierten: Von den Abiturienten waren insgesamt 1,2 \%, von den Studenten nur 0,3\% deutscher Nationalität. „Die Absicht der Anführer der Deutschen, die geistige Führung in den Händen der Deutschen zu halten, wird bei der Stärke des Assimilationsprozesses nicht gelingen, weil der überwiegende Teil der deutschen Jugend, die eine böhere Schule besuchen, bis zum Ende der Schulbildung in Sprache und Gefühl derart ungarisch wird, dass er vom Deutschtum als Nationalität gar nichts mehr wissen will ..." - fasste der

\footnotetext{
${ }^{28}$ SPIRA, German-Hungarian Relations and the Swabian Problem 74.

${ }^{29} \mathrm{Vgl}$. bei SEEWANN, Geschichte der Deutschen in Ungarn Band 2, 238: Schultypus „A“ = Sämtliche Fächer werden in der Minderheitensprache unterrichtet, Ungarisch ist Pflichtfach. Schultypus „B“: Ein Teil der Fächer wird in Ungarisch, ein Teil in der Minderheitensprache und ein Teil in beiden unterrichtet. Schultypus „C“: Alle Fächer werden in Ungarisch unterrichtet, lediglich Lesen und Schreiben in der Minderheitensprache ist Pflichtfach.

${ }^{30}$ Ebd, 176.

31 SPIRA, German-Hungarian Relations 184, 288; BELLÉR, Az ellenforradalmi rendszer nemzetiségi politikája 289.

32 Spira legt die „Statistik-Magie“ der ungarischen Regierung detailliert dar. SPIRA, German-Hungarian Relations 175, 182, 189-190; TilkovsZKY, A magyarországi német mozgalom válságának kibontakozása 409-411; SEEWANN, Geschichte der Deutschen in Ungarn, Band 1, 244-248.

33 SCHÖDL, Lange Abschiede 469; SEEWANN, Geschichte der Deutschen in Ungarn, Band 1, 244-248; SPIRA, GermanHungarian Relations 184, 288; BELLÉR, Az ellenforradalmi rendszer nemzetiségi politikája a válság küszöbén 289.

34 SCHWIND, Jakob Bleyer 122.
} 
Demograph Alajos Kovács, Leiter des Statistischen Zentralamtes die Situation 1936 zusammen. ${ }^{35}$

So wird ersichtlich, dass in der Schulfrage die Regierung, die Schulverordnung ohnehin nur halbherzig herausgab, sich ziemlich einfach hinter die Kirchen verstecken konnte und auf diese Weise die Umgestaltung der Schulen sabotieren konnte, auf der anderen Seite versuchte sie durch die örtlichen Verwaltungsapparate auf die Elternversammlungen Einfluss zu nehmen. Es gibt mehrere Beispiele, die zeigen, dass die frei abgehaltenen Elternverssammlungen oft für Typ A aussprachen, während - unter welcher Begründung auch immer - wiederholte Versammlungen eher im Regierungssinne entschieden. Somit war die Schullage ähnlich wie noch vor 1918.

Nach der Schulverordnung von 1935, die den Typ B verbreiten wollte aber nur bescheiden zur Ausführung kam, stieg der Bedarf an Lehrern an, die in deutscher Sprache unterrichten konnten, was $\mathrm{zu}$ einem Lehrermangel führte. ${ }^{36} \mathrm{Zu}$ einer spürbaren sogar übertriebenen Verbesserung kam es erst nach der quasi Gleichschaltung der Volksgruppe mit dem sog. Wiener Volksgruppenabkommen. Ungarn erließ im Schlepptau dieses Abkommens im Februar 1941 eine Schulverordnung, die ein einheitliches - wirkliches Minderheitenschulsystem mit Unterricht in der Muttersprache ermöglichte, gleich aber auch möglich machte, dass die Mischtypen beibehalten werden, wenn Eltern das wünschen. Damit behielt sich die Regierung wiederum das Feld der Beeinflussung für sich. Obwohl die Verwirklichung wieder Jahre in Anspruch nahm, entstanden jetzt auch höhere Schulen in großer Zahl, womit das ungarndeutsche Schulsystem komplett wurde.

Während in der Schulfrage die ungarische Ethnopolitik auf alte Mittel zurückgreifen konnte, forderte die Gründung der ersten landesweiten Organisation der Ungarndeutschen, des Ungarländischen Deutschen Volksbildungsvereins (UDV) neue Praktiken. Die Regierung versuchte den als Interessenvertretung gedachten Verein vielschichtig zu unterminieren. Ab jetzt wurde eine bewährte Praxis, dass sich das Innenministerium für die Annahme der Satzungen beinahe ein Jahr ließ und die Satzungen so ,abschwächte“, dass sie nicht mehr den Wünschen der Ungarndeutschen entsprachen. In den 30er und 40er Jahren ähnlich erging es bei der Gründung des neuen von Fran₹ Basch angeführten, radikaleren Vereins, des Volksbundes der Deutschen in Ungarn und dessen Jugendorganisation, Deutsche Jugend (DJ). Im Falle der Studentenvereinigung Suevia verzögert man die Genehmigung der Satzungen über 10 Jahre hinaus. ${ }^{37}$

Darüber hinaus war man bestrebt den Vorstand mit regierungstreuen Personen aufzufüllen. So durfte Jakob Bleyer, der Initiator des UDV nur als Geschäftsführer agieren, während den Vorsitz der frühere Außenminister, Gustav Gratz bekam, übrigens auch deutscher Abstammung. ${ }^{38}$

Trotz Verzögerung durfte die oben doch nachgiebige Regierung jedoch wieder mit dem Zuvorkommen der örtlichen Apparate rechnen, die sehr fleißig waren, wenn es um die Ortsgruppengründungen des UDV ging. Die ungarische Verwaltung verhinderte, dass der UDV auf territorialer Ebene die gesamte deutsche Minderheit erreichen und eingliedern konnte. Im Komitat Veszprém durfte er beispielsweise überhaupt keine Ortsgruppe gründen, im Komitat Pest bis 1926 nicht, im Komitat Baranya ließ der Obergespan die vorab gegründeten Gruppen 1927

\footnotetext{
${ }^{35}$ KovÁCS, A németek helyzete Csonka-Magyarországon 20.

36 Vgl. SPIRA, The German-Hungarian-Swabian Triangle 59.

${ }^{37}$ SPANNENBERGER, Der Volksbund der Deutschen in Ungarn 48-51, 154-165.

38 SPANNENBERGER, Der Volksbund der Deutschen in Ungarn 50.
} 
auflösen und knüpfte jede spätere Gründung an eine von ihm erteilte Genehmigung. ${ }^{39}$ Hier gelang es erst zum Ende des Jahrzehnts mit der persönlichen Fürsprache des Ministerpräsidenten nahezu 30 Ortsgruppen ins Leben zu rufen. ${ }^{40}$

So ist es nicht verwunderlich, dass der UDV das größte Gewicht in den Gebieten östlich der Donau erreichen konnte, und zwar in den Komitaten Pest-Pilis-Solt-Kiskun und Bács-Bodrog: in den 41 mehrheitlich deutschen Gemeinden besaß der UDV 40 Ortsgruppen. Ähnlich positiv war die Situation auch in Nordwestungarn, in den Komitaten Sopron, Moson, Győr, Komárom und Esztergom: hier gab es von den 31 mehrheitlich deutschen Gemeinden in 29 eine Ortsgruppe. In den Hochburgen, in denen die meisten Deutschen lebten, in Budapest und Umgebung beziehungsweise in Südtransdanubien („Schwäbische Türkei“: die Komitate Tolna, Baranya, Somogy) war das Ergebnis aus Sicht des UDV jedoch deprimierend, denn in diesen Gebieten konnte er nur in 37 Prozent der in Frage kommenden Dörfer auftreten. In den 82 deutschen Gemeinden der verbleibenden drei Komitate, Veszprém, Vas und Zala, existierte insgesamt nur eine einzige Ortsgruppe. ${ }^{41}$

\section{Minderheitenrecht und behördliche Praxis in der Zwischenkriegszeit}

Die unteren Verwaltungsorgane unterlagen trotz der Verbürgerlichung der Gesellschaft durchweg dem Zwang, das Vereinsleben streng überwachen $\mathrm{zu}$ müssen, insbesondere dann, wenn Organisationen dieser Art auch ein latent oder manifestiert ethnisches Moment verkörperten. Die Behörden waren so sozialisiert, dass sie jede Art von Eigenorganisation als einen störenden Faktor betrachteten. Es überstieg die Vorstellungen der damaligen Verwaltungsorgane, dass eine Organisation sozusagen selbstständig wurde und auch in Bereichen tätig war, die der autoritäre Staat nicht überwachte. Das freie Vereinsleben war einfach nicht Teil der damaligen gesellschaftlichen Kultur: Was man nicht vollkommen kontrollieren konnte, das generierte Angst.

Darauf ist auch zurückzuführen, dass die deutsche Bewegung ebenfalls keine Initiative war, die aus der Basis der Bevölkerung entstanden war, sondern die man versuchte, von oben in Gang zu setzen. In vielen Fällen wurde gerade das von den kommunalen Behörden beanstandet, denn damit hielt man es für belegt, dass es sich um eine Propaganda-Bewegung handelte, die von Budapest aus gesteuert wurde. Man bemerkte jedoch nicht, dass dieses Phänomen zugleich zeigte, wie dürftig die Kultur lokaler Selbstorganisation war und gerade diese Autoritäten diese Welt repräsentierten, in der höchstens das unanzweifelbar war, was auf eine genau abgesprochene Initiative der örtlichen Trias (Notar, Lehrer, Pfarrer) zustande kam: vor allem Lesezirkel, Schützenvereine usw.

Ist eine Ortsgruppe des UDV entstanden und hat mit ihrer üblichen Tätigkeit begonnen, fiel sie unter ständige und feste Kontrolle. Bei den einzelnen Veranstaltungen gab es stets Spitzel, die über diesen Bericht erstatten, oft mal war die Gendarmerie oder die Polizei vor Ort, bei größeren und wichtigeren Veranstaltungen sogar der Oberstuhlrichter, d. h. der Leiter der

\footnotetext{
${ }^{39}$ FLACH, Ortsgruppengründungen des Ungarländischen Deutschen Volksbildungsvereins 4.

${ }^{40}$ FÜZES, Nemzetiségi ügyek dokumentumai Baranyában, Dokument Nr. 51.

${ }^{41}$ BELLÉR, Az ellenforradalmi rendszer nemzetiségi politikájának kialakulása 279-280; SPIRA, German-Hungarian Relations 161-163.
} 
Verwaltungseinheit Kreis zugegen. Man achtete insbesondere auf zwei Sachen: einmal, dass die Veranstaltung nicht politisch ist, wobei man sehr flexibel alles politisch abstempeln konnte, was man wollte - so an erster Stelle, wenn die Redner die Wünsche der Deutschen in Ungarn äußerten. In Berufung auf das politische Gepräge einer Veranstaltung, konnte man sofort eingreifen und diese auflösen. Zweitens war man bestrebt, dass sich die Tätigkeit des Vereins sich nur auf die wirklichen Mitglieder erstreckte. Bei den Ungarndeutschen war es dagegen Usus, dass pro Familie nur eine Person, meistens der Mann der Organisation beitrat, bei den Veranstaltungen jedoch auch die Familienangehörigen erschienen. So zeigte man sich hier normalerweise flexibel, und erst in den 30-er Jahren, als durch die neue Generation die Ortsgruppen richtig belebt wurden, versuchte man diese Regel einzuhalten. In erster Linie wollte man die Vereinsmitglieder anderer Ortsgruppen fernhalten, damit keine Massenveranstaltungen entstehen.

Noch unsympathischer wurde das deutsche Vereinsleben als es bereits vehementere Töne anschlug. Und während die Lageberichte des Ordens des Standes der Tapferen (Országos Vitézi Szék) zum Schutz der Nation im Allgemeinen selbst 1937 oder 1938 keine Probleme bei den Deutschen in Ungarn feststellten, man das Phänomen in einzelnen Fällen erst ab 1935 als pangermanisch titulierte, im Komitat Pest-Pilis-Solt-Kiskun aufgrund der späten Gründungen sogar erst ab 1938, doch auch da meist die Gründung von ein paar UDV-Ortsgruppen gemeint waren, verbreiteten die Ämter in den Gemeinden und Kreisen zuweilen bereits in den 1920erJahren mit der pangermanischen Gefahr Angst. Im Jahr 1937 bezeichnete der Oberstuhlrichter des Kreises Buda-környék beispielsweise auch eher die einzeln oder in Gruppen eintreffenden deutschen Besucher sowie das Auftauchen von Presseerzeugnissen aus Deutschland als einen pangermanischen Faktor. Daraus lässt sich erkennen, dass die Reizschwelle der einzelnen Behörden in dieser Hinsicht sehr unterschiedlich war. ${ }^{42}$

Der Orden des Standes der Tapferen wurde bei der Beurteilung der Situation der Deutschen bereits zur Zeit des Anschlusses jedoch sehr pessimistisch: „Da sich herausstellte, dass sich das großdeutsche Ereignis auf unsere deutschsprachigen Ungarn mit einem überaus ideellen Einfluss auswirkte und sich ibr treustes und aufrichtigstes inneres Empfinden beinahe in einer Parteisolidarität zeigte, sehe ich es so, dass die Staatstreue hier auf schwachen Füßen steht. Es gilt, ein neues und geschicktes System im Umgang mit den Deutschsprachigen zu finden, und das muss unter der größten Gebeimbaltung so bald wie möglich angewandt werden. ${ }^{\text {*A3 }}$

Mit dem Ausbau der Organisation wurde die Aufmerksamkeit zunehmend größer. 1938 bat der Obergespan die Oberstuhlrichter im Komitat Baranya, die deutsche Bewegung ,mit der größten Wachsamkeit beobacbten zu lassen und insbesondere deren bekannte Vertreter vor Ort zu kontrollieren". Über die Aufwiegler im Inland, die keine ungarischen Staatsbürger waren, bat man um sofortige

\footnotetext{
${ }^{42}$ Vgl. az Országos Vitézi Szék havi nemzetvédelmi helyzetjelentéseit Pest-Pilis-Solt-Kiskun vármegyéből [Monatlicher Lagebericht des Országos Vitézi Szék zum Schutz der Nation aus dem Komitat Pest-Pilis-Solt-Kiskun] - MNL PML IV 401a, Pest-Pilis-Solt-Kiskun vármegye fóispánjának bizalmas iratai, 25/1937, 13/1938; Buda-környéki járás főszolgabírája Pest-Pilis-Solt-Kiskun vármegye főispánjának, Budapest, 1937. szeptember 10. [Der Oberstuhlrichter des Kreises Buda-környék an den Obergespan des Komitats Pest-Pilis-Solt-Kiskun, Budapest, 10. September 1937] MNL PML IV 401a, Pest-Pilis-Solt-Kiskun vármegye főispánjának bizalmas iratai, 3/1937.

43 Országos Vitézi Szék nemzetvédelmi helyzetjelentése 1938. február hóról, Pécs, 1938. március 19. [Lagebericht des Országos Vitézi Szék zum Schutz der Nation vom Februar 1938, Pécs, 19. März 1938] - MNL BML IV 401a, Baranya vármegye főispánjának bizalmas iratai, 69/1938.
} 
Meldung. ${ }^{44}$ Eine Veränderung stellte sich nur insofern ein, dass der Obergespan in diesen Fällen mit Nachdruck darauf hinwies, schnell informiert zu werden, im Übrigen ging man mit der gewohnten Praxis vor. Vermutlich resultierte diese geringfügige Veränderung aus den Ereignissen des Frühjahrs 1938 (Anschluss), doch ist sie eventuell auch darauf zurückzuführen, dass im Komitat Baranya Iván Blaskovich ernannt worden war, jener Oberstuhlrichter des Kreises Hegyhát, der auch bis dahin jeder Regung der Deutschen in seinem Kreis besonders große Aufmerksamkeit gewidmet hatte und dieses System nun auf das gesamte Komitat einheitlich anzuwenden wünschte.

Dass sich das um Fran₹ Basch etablierte radikale Lager bei der Neupositionierung der UDVOrtsgruppen beziehungsweise der Gründung neuer Gruppen mit der bisherigen Praxis brechen wollte, laut der die nicht deutschgesinnte Intelligenz (Pfarrer, Geistlicher, Kaplan, Kreisnotar, Notar, Hilfsnotar usw.) in den Vorstand der einzelnen UDV-Ortsgruppen gewählt wurden, frustrierte die Behörden sehr. In Abaliget hätten die Einwohner bei der Gründung der Ortsgruppe im Jahr 1934 diese frühere Methode weiterhin adaptiert, was Basch, der bei dem Ereignis anwesend war, jedoch zu verhindern wusste. ${ }^{45}$ Für die Behörden wurde es bedeutend schwerer, die Ortsgruppen zu überwachen, es gab nämlich keine internen Informanten mehr und die Kontrolle erforderte damit eine sehr viel größere Organisationsarbeit.

Das zunehmend rege Leben in der UDV stellte die lokalen Amtsträger, die eine solche Dynamik nicht gewohnt waren, vor eine Herausforderung, das neue Phänomen bedeutete für sie nicht nur mehr Arbeit, sondern machte sie auch schwieriger. Um mit der Aufgabe fertig zu werden, versuchte man sich mit verschiedenen Lösungsmethoden. Der Oberstuhlrichter des Kreises Pécsvárad hielt es beispielsweise für zweckmäßig, die „Übertreibenden“ vollkommen lahmzulegen, zudem sollte die lokale Intelligenz - die Pfarrer und Lehrer - sich mehr um die einheimischen Deutschen (von denen er schon 1936 mehr als 80 Prozent für unzuverlässig hielt) kümmern, damit diese sich nicht der UDV zuwandten. Er erwartete von ihnen auch eine vorbildlichere Haltung im Hinblick auf die Treue zur Nation. Schließlich beabsichtigte er, den Deutschen mit einem langfristigen Senken oder dem vollkommenen Entzug der wirtschaftlichen Vergünstigungen den Boden unter den Füßen wegzuziehen. ${ }^{46}$ Man nahm also nicht wahr, dass der wirtschaftliche Positionsverlust der Deutschen in der ersten Hälfte der dreißiger Jahre ein Grundpfeiler für das verstärkte Interesse an der radikaleren Richtung war.

Es gab Ansichten, die zwischen der gemäßigten und der radikalen Richtung innerhalb des UDV keinen wesentlichen Unterschied sahen und die Meinung vertraten, beide würden ,für die großdeutsche Zukunft kämpfen, lodern ", den Interessen Hitler-Deutschlands dienen und sich nur im Tempo unterscheiden beziehungsweise darin, dass die eine Richtung „offener, die andere beimtückischer"sei. Somit erachtete man den Kampf gegen beide für notwendig, sie sollten nicht mit

\footnotetext{
${ }^{44}$ Baranya vármegye főispánja a főszolgabíráknak és Mohács polgármesterének, Pécs, 1938. május 7. [Der Obergespan des Komitats Baranya an die Oberstuhlrichter und den Bürgermeister von Mohács, Pécs, 7. Mai 1938] - MNL BML IV 401a, Baranya vármegye főispánjának bizalmas iratai, 104/1938.

45 Pécsi járás főszolgabírája Baranya vármegye főispánjának, Pécs, 1934. október 29. [Der Oberstuhlrichter des Kreises Pécs an den Obergespan des Komitats Baranya, Pécs, 29. Oktober 1934] - MNL BML IV 401a, Baranya vármegye főispánjának bizalmas iratai, 244/1934.

46 Pécsváradi járás főszolgabírája Baranya vármegye főispánjának, Pécsvárad, 1936. március 9. [Der Oberstuhlrichter des Kreises Pécsvárad an den Obergespan des Komitats Baranya, Pécsvárad, 9. März 1936] - MNL BML IV 401a, Baranya vármegye főispánjának bizalmas iratai, 73/1936.
} 
Beschimpfungen und lauten Worten, sondern durch Taten in den Hintergrund gedrängt werden. ${ }^{47}$ „Dieser Gesellschaft dürfte man in keiner Form staatliche Hilfe zukommen lassen, weil selbst die sanftere Formation [...] nicht ungarisch gesinnt ist, und es ist nicht ungarisch gesinnt, was Deutsch ist" - schrieb der Kreisnotar von Babarc. ${ }^{48}$ Für problematisch hielt er auch, dass an den Universitäten pangermanische Lehrer unterrichteten, wodurch die neu ausgebildeten Lehrer für Volksschulen und Gymnasien von Anfang an mit diesen Ideen infiziert würden. Geduldet werden konnte nach dieser Auffassung also nur was Ungarisch, also nicht Deutsch, war. Zu sehen war auch, dass die Behörde sich, je näher sie an dem Phänomen selbst dran war, umso ungeduldiger verhielt. Gleichzeitig konnte ein Amtsträger, der im Sinne der lokalen Gemeinschaft verantwortlich handelte, die Gefahr einer Eskalation senken, wenn er nicht jede heikle Angelegenheit weiterleitete.

Laut dem Notar von Palotabozsok hatte die Distanzierung der Deutschen vom ungarischen Staat bereits mit dem Bauernbund (Anfang des 20. Jahrhunderts) begonnen und konnte, seiner Ansicht nach, nicht mit normalen Mitteln, sondern nur mit harter Hand rückgängig gemacht werden. Den satzungswidrig wirkenden UDV hätte er, wäre es nach ihm gegangen, einfach aufgelöst und den Deutschen die bis dahin „auf dem Präsentierteller servierten“ wirtschaftlichen Vergünstigungen ebenfalls entzogen, die die wohlhabenderen Bauern in Palotabozsok ohnehin „hochmütig“ ablehnten. ${ }^{49}$ Der Kreisnotar der Gemeinde Lánycsók wollte nur erreichen, dass die zentralen Gesandten des UDV von der Gemeinde ferngehalten werden, damit die Ruhe weiterhin erhalten blieb.

Im Jahr 1936 forderte der Obergespan des Komitats Baranya von allen Kreisnotariaten wegen der Zweipoligkeit der UDV Berichte über das Verhalten und die Einstellung der Deutschen in den einzelnen Ortschaften. Diese fasste er zusammen und legte sie, indem er die Größe der Gefahr gewissermaßen überbetonte, dem Innenminister vor, außerdem formulierte er einen komplexen Entwurf mit Vorschlägen zum Umgang mit der Frage. Zum einen sollte eine erneute Aufnahme der inzwischen in Illegalität gedrängte Basch-Gruppe in den UDV verhindert werden und eine Neuwahl für die Besetzung der Ämter im UDV durchgeführt werden, bei der die restlose Entfernung der „Übertreiber“ als Ordnungsprinzip gelten sollte. Zum anderen hielt er auf kommunaler Ebene weiterhin für notwendig, die Bevölkerung von dem UDV fernzuhalten, weil er die Ansicht vertrat, dass „die Zuverlässigkeit der Menschen endgültig erlischt“, wenn das Selbstbewusstsein einmal erwache. Darüber hinaus wollte er „der weiteren Verbreitung und Erstarkung des Deutschtums mit präventiven Maßnahmen" einen Riegel vorschieben, unabhängig von der internationalen Konstellation. Dafür sollten im Zuge der Durchführung des Ansiedlungsgesetzes ,in die gemischtsprachigen oder unter dem Gesichtspunkt der Expansion der Nationalitäten maßgeblichen Gebiete ausschließlich Familien mit mehreren Kindern und ungarischer Muttersprache angesiedelt werden". Als Beamte

\footnotetext{
${ }^{47}$ Kölkedi körjegyző a mohácsi járás főszolgabírájának, Mohács, 1936. március 5. [Der Kreisnotar von Kölked an den Oberstuhlrichter des Kreises Mohács, Mohács, 5. März 1936] - MNL BML IV 401a, Baranya vármegye főispánjának bizalmas iratai, 73/1936.

${ }^{48}$ Babarci körjegyző a mohácsi járás főszolgabírájának, Babarc, 1936. február 29. [Der Kreisnotar von Babarc an den Oberstuhlrichter des Kreises Mohács, Babarc, 29. Februar 1936] - MNL BML IV 401a, Baranya vármegye föispánjának bizalmas iratai, $73 / 1936$.

49 Palotabozsoki körjegyző a pécsváradi járás főszolgabírájának, Palotabozsok, 1936. február 26. [Der Kreisnotar von Palotabozsok an den Oberstuhlrichter des Kreises Pécsvárad, Palotabozsok, 26. Februar 1936] - MNL BML IV 401a, Baranya vármegye föispánjának bizalmas iratai, 73/1936.
} 
hielt er nur Personen für geeignet, die ungarischer Abstammung waren, aber gut Deutsch sprachen, ferner wollte er staatliche Angestellte (Post, Eisenbahn) mit nicht-ungarischer Muttersprache in ungarische Gebiete versetzen. Die Zuverlässigkeit der Dorflehrer sollte dadurch gewährleistet werden, dass man sie nicht wählte, sondern ernannte. Schließlich empfahl der Obergespan auf Vorschlag der Stuhlrichter, die wirtschaftlichen Förderungen vonseiten des Staates zu beschneiden beziehungsweise vollkommen zu streichen, da die wohlhabenden Schwaben gerade durch diese in ihre vorteilhafte wirtschaftliche Situation gelangt seien. Somit stellte er sich die Regelung der Lage nicht durch die Auflösung des Vereinslebens oder dessen künstlicher Lahmlegung vor, sondern durch den Beschluss derartiger Maßnahmen im Hintergrund. ${ }^{50}$

Der Obergespan des Komitats Baranya erachtete es außerdem für notwendig, als Gegengewicht zu den „pangermanischen“ Presseerzeugnissen und anderen Publikationen Volksbüchereien an den wichtigsten Orten einzurichten sowie ein System von Informanten auszubauen, durch das diese das Vertrauen der Bevölkerung erlangten und so einerseits Informationen erhielten, andererseits die Bevölkerung in die gewünschte Richtung beeinflussten. ${ }^{51}$

Die Praxis in den einzelnen Ortschaften zeigte, dass die Kenntnisnahme der Gründung der legalisierten Basch-Gruppe verkörpernden Volksbundortsgruppen - ähnlich wie bei der Gründung der UDV-Ortsgruppen - ebenso schleppend voranging wie bereits die Annahme der Satzungen. Das Hinauszögern der rechtlichen Genehmigung war offensichtlich Teil der allgemeinen Handhabung, denn sonst hätte das Innenministerium im Herbst 1940 nicht auf eine Beschleunigung des Prozesses gedrängt und vorgeschrieben, die bereits angemeldeten, doch noch nicht entschiedenen Fälle innerhalb von 8 Tagen, die neuen Anmeldungen hingegen innerhalb von 15 Tagen zur Kenntnis zu nehmen. Im Komitat Baranya gab es keine solche Rückstände, aber der Obergespan änderte seine Einstellung auch darüber hinaus: Er kritisierte das Verhalten der örtlichen Richter und Notare, da sie bei offiziellen Angelegenheiten - z. B. Luftschutzarbeiten usw. - darauf bestanden, dass man das Volksbund-Abzeichen ablegte. Er argumentierte, dass der Verein gesetzmäßig sei und sich somit jeder zu seiner Mitgliedschaft bekennen könne, die Organisation also nicht behindert oder gehemmt werden dürfe, nicht nach einem gesonderten Verfahren zu behandeln und auf taktlose oder unüberlegte Weise zu provozieren sei. Ein solches Vorgehen vonseiten der Behörden diskreditierte seiner Ansicht nach die Staatsmacht, die VolksbundMitglieder könnten sich behelligt fühlen, daher sollten auch tadelnde Gespräche mit den Mitgliedern der Organisation unter vier Augen vermieden werden. Ein Klärung wäre bei solchen Gelegenheiten ohnehin nicht möglich, denn es stünden zwei Behauptungen im Raum, doch würden Fälle dieser Art die Verwaltung vor der breiten Öffentlichkeit als nationalitätenfeindlich zeigen. $^{52}$

\footnotetext{
${ }^{50}$ Baranya vármegye főispánja a magyar kir. belügyminiszternek, Pécs, 1936. április 24. [Der Obergespan des Komitats Baranya an den königl. ungarischen Innenminister, Pécs, 24. April 1936] - MNL BML IV 401a, Baranya vármegye főispánjának bizalmas iratai, 91/1936.

${ }^{51}$ Baranya vármegye föispánja a magyar kir. belügyminiszternek, Pécs, 1936. június 22. [Der Obergespan des Komitats Baranya an den königl. ungarischen Innenminister, Pécs, 22. Juni 1936] - MNL BML IV 401a, Baranya vármegye főispánjának bizalmas iratai, 125/1936.

${ }^{52}$ M. Kir. Belügyminiszter a törvényhatóságok első tisztviselőinek stb., Budapest, 1940. október 17. [Der Königl. Ung. Innenminister an die obersten Beamten der Munizipalbehörden usw., Budapest, 17. Oktober 1940] - MNL BML IV 401a, Baranya vármegye főispánjának bizalmas iratai, 551/1940; Baranya vármegye fớispánja Balogh Pál miniszteri tanácsosnak, m. kir. Belügyminisztérium, Pécs, 1940. október 22. [Der Obergespan des Komitats Baranya an den
} 
Die Führung des Komitats Baranya war sich also im Klaren darüber, dass das angespannte Verhältnis unter anderem auch auf das Verhalten der Behörden zurückzuführen war. Es fiel beispielsweise auf, dass die Auseinandersetzungen im Kreis Pécsvárad heftiger waren als in den Kreisen Hegyhát und Mohács, in denen die deutsche Bewegung aktiver war, also wurde der zuständige Oberstuhlrichter angewiesen, die Situation zu regeln. In Mekényes war vermutlich das überaus patriotische Verhalten des Gemeindenotars dafür verantwortlich, dass der Volksbund die gesamte Dorfbevölkerung für sich gewinnen konnte. Hier bat man den Oberstuhlrichter von Sásd, entsprechende Maßnahmen einzuleiten, gegebenenfalls auch die Suspendierung des Notars, sollte dieser nicht in der Lage sein, das Vertrauen der Gemeinde wiederzuerlangen. ${ }^{53}$

Vieles war von den Fähigkeiten und dem „,politischen“ Gespür der Mitarbeiter in den Behörden abhängig, denn ein für die ungarischen Ämter günstigeres Ergebnis konnte man mit subtilen Mitteln durchaus erreichen. „Eine positive Veränderung zeigt sich in diesem Bereich in der Gemeinde Solymár, wo die Arbeit des Obernotars als erfolgreich zu bezeichnen ist, er bält die Menschen sowobl im gesellschaftlichen als auch im wobltätigen Bereich zusammen, bildet ein Gegengewicht zum Wirken des Volksbundes, den er entschieden geschwächt hat. ${ }^{\text {'54 }}$

Dennoch ist auch zu sehen, dass die Einstellung der Behörden zum Volksbund nicht nur eine Reaktion auf die Tätigkeit des Volksbundes war, sondern am ehesten davon abhängig war, welche weiteren Phänomene es in dem jeweiligen Gebiet außer dem Volksbund gab, welche anderen Organisationen aktiv waren, die ebenfalls das Interesse der Behörden weckten und sie Tag für Tag vor Aufgaben stellten. Während im Komitat Baranya eindeutig der Volksbund im Zentrum der behördlichen Überwachung stand, verteilte sich die Aufmerksamkeit im Komitat Pest auf mehrere Organisationen, denn hier mussten die Pfeilkreuzler, die Sozialdemokraten und die ungarischen Nationalsozialisten gemessen an ihrer Stärke ebenfalls berücksichtigt werden.

Vermutlich ging man in der überwiegenden Mehrzahl der Fälle mit einer kühlen, gemessenen und akkuraten Sachlichkeit vor, die jegliche Flexibilität vermissen ließ, doch es gab auch eine ganze Reihe von Übergriffen, die vor allem durch die nach Deutschland geschickten Volksbund-Berichte dokumentiert wurden. Eine typische Form der Repressalien war es, dass der Gemeindevorstand oder höhere Verwaltungsorgane darum baten, die Männer, mit denen man Schwierigkeiten hatte, zum Militärdienst einzuberufen. So geschah es auch 1938 in Mágocs, wo es János Schuller d. J., „,dem starken Agitator der lokalen pangermanischen Bewegung“, so erging. Man achtete außerdem darauf, dass er möglichst in ein rein ungarisches Regiment, zum Beispiel in die Tiefebene, kam, um auf diese Weise seine ,unter dem Gesichtspunkt der ungarischen Staatsidee zu

\footnotetext{
Ministerialrat Pál, Balogh, königl. ung. Innenministerium, Pécs, 22. Oktober 1940] - MNL BML IV 401a, Baranya vármegye főispánjának bizalmas iratai, 551/1940; Baranya vármegye főispánja a m. kir. miniszterelnöknek, Pécs, 1941. augusztus 22. [Der Obergespan des Komitats Baranya an den königl. ung. Ministerpräsidenten, Pécs, 22. August 1941] - MNL BML IV 401a, Baranya vármegye főispánjának bizalmas iratai, 522/1941; Baranya vármegye főispánja a mohácsi járás főszolgabírájának, Pécs, 1941. március 6. [Der Obergespan des Komitats Baranya an den Oberstuhlrichter des Kreises Mohács, Pécs, 6. März 1941] - MNL BML IV 401a, Baranya vármegye főispánjának bizalmas iratai, 131/1941. ${ }^{53}$ Hegyháti járás főszolgabírája Baranya vármegye főispánjának, Sásd, 1940. szeptember 2., Baranya vármegye főispánja a hegyháti járás főszolgabírájának, Pécs, 1940. szeptember 5. [Der Oberstuhlrichter des Kreises Hegyhát an den Obergespan des Komitats Baranya, Sásd, 2. September 1940] - MNL BML IV 401a, Baranya vármegye főispánjának bizalmas iratai, 367/1940.

${ }^{54}$ Buda-környéki járás főszolgabírája a főispánnak, Budapest, 1942. január 12. [Der Oberstuhlrichter des Kreises Budakörnyék an den Obergespan, Budapest, 12. Januar 1942] - MNL BML IV 401a, Pest-Pilis-Solt-Kiskun vármegye föispánjának bizalmas iratai, 8/1941.
} 
beanstandende" Einstellung korrigieren zu können. Die ungarische Honvéd-Armee sollte sogar den aufgrund einer Studienreise nach Deutschland gültigen Aufschub bis zum 1. Oktober 1938 zurücknehmen und ihn umgehend, noch Anfang 1938 zum Wehrdienst einziehen. „Um die Gemeinde in ungarischem Geist erhalten zu können, ist dies unbedingt notwendig, und daher bitte ich Sie, alles daran₹usetzen, besagte Person außer der Reibe einzuberufen, vor allem, da diese am 23. Januar 1938 beabsichtigt zu heiraten". Das Verteidigungsministerium zeigte sich kooperativ und traf im Februar 1938 entsprechende Maßnahmen. In ähnlicher Weise wollte man einen Studenten der Veterinärmedizin aus Szalatnak isolieren, bei dem man zudem befürchtete, dass er mit seiner zukünftigen Niederlassung als Tierarzt die gesamte Umgebung verseuchen könnte. 1939 sollte István Reitinger aus Csikóstöttös entfernt werden, der gemeinsam mit Gáspár Bayerle die einheimische Jugend mobilisierte. ${ }^{55}$

Im Fall Bayerles, der von Dorf zu Dorf zog und so die Bewegung im Kreis Hegyhát organisierte, wollte man nicht nur mit dem Mittel der Einberufung vorgehen, sondern geradewegs sein Studium der Veterinärmedizin vereiteln; man ging davon aus, dass seine Tätigkeit nach Beendigung des Studiums und bei einer Niederlassung als Tierarzt mit sicherem finanziellen Hintergrund mit Gewissheit schädliche Auswirkungen hätte. Eine ähnliche Praxis zeigte sich auch im Komitat Pest-Pilis-Solt-Kiskun. In einigen Fällen sprachen die Behörden von der „positiven“ Wirkung des Wehrdienstes. 1942 stellte sich beispielsweise in der Umgebung von Baja eine „Windstille“ ein, da der Bajaer Rechtsanwalt Pál Flach, eine der führenden Persönlichkeiten des Volksbundes vor Ort, gerade seinen Militärdienst ableistete. Von Zeit zu Zeit waren auch die SSRekrutierungen von ähnlicher Wirkung. ${ }^{56}$

Darüber hinaus entstand auf lokaler Ebene auch ein System angewandter Strafen. Im Oktober 1939 ließ der Kreisnotar von Kakasd die deutschen Jugendlichen, die sich abends zwischen 19 und 20 Uhr in den Gemeinden Kakasd und Belac (ab 1935 unter dem Namen Kakasd zusammengelegt) auf der Straße aufhielten - was im Allgemeinen kein Einzelfall war - vom

\footnotetext{
${ }^{55}$ Másolat a 8004/1938. VII. res. B.M. sz. iktatmány mellékletéről. Mágocs község elöljáróságától a járási Testnevelési és Népgondozói Kirendeltségnek, Sásd, Mágocs, 1937. december 22. [Abschrift der Beilage der Akte Nr. 8004/1938. VII. res. B.M. Der Gemeindevorstand Mágocs an die Außenstelle für Leibeserziehung und Volkspflege, Sásd, Mágocs, 22. Dezember 1937]; M. Kir. Honvédelmi Miniszter a M. Kir. belügyminiszternek, Budapest, 1938. április 23. [Der Königl. Ung. Verteidigungsminister an den Königl. Ung. Innenminister, Budapest, 23. April 1938] - MNL BML IV 401a, Baranya vármegye főispánjának bizalmas iratai, 115/1938; Hegyháti járás főszolgabírája a főispánnak, Sásd, dátum nélkül [Der Oberstuhlrichter des Kreises Hegyhát an den Obergespan, Sásd, undatiert] - MNL BML IV 401a, Baranya vármegye főispánjának bizalmas iratai, 33/1939; Hegyháti járás főszolgabírája a főispánnak, Sásd, 1939. március 9. [Der Oberstuhlrichter des Kreises Hegyhát an den Obergespan, Sásd, 9. März 1939] - MNL BML IV 401a, Baranya vármegye főispánjának bizalmas iratai, 108/1939.

${ }^{56}$ Hegyháti járás főszolgabírája Baranya vármegye főispánjának, Sásd, [1938. március eleje] [Der Oberstuhlrichter des Kreises Hegyhát an den Obergespan des Komitats Baranya, Sásd, Anfang März 1938] - MNL BML IV 401a, Baranya vármegye főispánjának bizalmas iratai, 33/1939; Hegyháti járás főszolgabírája Baranya vármegye főispánjának, Sásd, [1938. március eleje] [Der Oberstuhlrichter des Kreises Hegyhát an den Obergespan des Komitats Baranya, Sásd, Anfang März 1938] - MNL BML IV 401a, Baranya vármegye főispánjának bizalmas iratai, 33/1939; Kalocsai járás főszolgabírája a m. kir. 44. számú honvéd kiegészítő parancsnokság kirendeltségének, Kalocsa, 1942. június 12. [Der Oberstuhlrichter des Kreises Kalocsa an die Außenstelle der königl. ung. ergänzenden Honvéd-Kommandantur Nr. 44, Kalocsa, 12. Juni 1942] - MNL BKML IV 903a, Pest-Pilis-Solt-Kiskun vármegye kalocsai járása főszolgabírája elnöki iratai, 73/1942; Nemesnádudvar község elöljárósága a kalocsai járás főszolgabírójának, Nemesnádudvar, 1942. június 10. [Der Gemeindevorstand Nemesnádudvar an den Oberstuhlrichter des Kreises Kalocsa, Nemesnádudvar, 10. Juni 1942] - MNL BKML IV. 903a, Kalocsai járás főszolgabírájának elnöki iratai, 15. doboz, 1942, 1/1942; Kalocsai járás főszolgabírája a föispánnak, Kalocsa, 1942. április 5. [Der Oberstuhlrichter des Kreises Kalocsa an den Obergespan, Kalocsa, 5. April 1942] MNL BKML IV 903a, Kalocsai járás főszolgabírájának elnöki iratai, 15. doboz, 1942, $3 / 1942$.
} 
Gemeindediener zusammenschreiben. Es handelte sich dabei um etwa 20 Jugendliche, von denen diejenigen über 18 Jahre mit einer Geldbuße belegt, die übrigen zu einer Verhandlung am Polizeigericht vorgeladen wurden. Die Jugendlichen hatten angeblich keinen Lärm gemacht, somit bat der Parlamentsabgeordnete Heinrich Mühl den Vizegespan, den Kreisnotar anzuweisen, derartige Behelligungen zu unterlassen. Das Oberstuhlgericht sprach von deutschen Jugendlichen, die sich unter der Führung Mühls befänden, man warf ihnen regelmäßige Ruhestörung und skandalöses Verhalten vor, was das gegen sie eingeleitete Verfahren rechtfertige. Müblwurde zudem so hingestellt, als zeige er die Leute ständig unbegründet an. ${ }^{57}$

Die ungarischen Organe unterzogen die Mitglieder des Volksbundes sowie seiner Jugendgruppen mit den unterschiedlichsten Begründungen einer verschärften Überwachung, sie wurden in Gewahrsam genommen oder für eine längere oder kürzere Zeit verhaftet. Mal zeigte man sie wegen der Gründung geheimer Gesellschaften an, mal wegen der Gefahr einer gesundheitlichen Schädigung, da sich die Jugendlichen angeblich an ungeeigneten Orten trafen. Die aus Deutschland adaptierten Symbole (das Bild oder Porträt des Führers, Fahnen mit Hakenkreuz usw.) waren - keineswegs unbegründet - ein rotes Tuch für die Gendarmerie, die Beschlagnahmung dieser stand in der Zeit vor 1942 auf der Tagesordnung, und in vielen Fällen folgte darauf eine Verhaftung. ${ }^{58}$

Im April 1941 wurde János Jockl, der Jugendführer des Volksbundes in Máriakéménd, insultiert. Bei der Luftschutzbereitschaft befahl ihm der Notar der Gemeinde das VolksbundAbzeichen abzulegen, er kam der Aufforderung nach, doch der Notar sagte nach dem Bereitschaftsdienst zu ihm: „Benimm dich ordentlich, du Schwein, du Vaterlandsverräter, du gehörst an den Galgenstrick. Wenn sich das Blatt der Zeit wendet, werden wir dich samt deinem Vater auf der Straße erschießen, damit die anderen sehen, wie es solchen Schurken ergeht, wie ihr es seid. "Dabei versetzte er ihm einen Schlag aufs Auge. Der Fall wurde wahrscheinlich untersucht, denn der Obergespan berichtete, dass der Jugendführer János Jockl in der vergangenen Zeit Bereitschaft zu Ausschweifungen gezeigt habe, daher habe es der Notar für notwendig gehalten, ihn höflich auf das Einhalten der Gesetze und Verordnungen aufmerksam zu machen. Die Aussage eines Augenzeugen untermauert allerdings eher die Version Jockls. ${ }^{59}$

Besonders kritisiert wurden die Übergriffe vonseiten der Behörden im Komitat Szatmár, in der Batschka, in den rückgegliederten Teilen des Komitats Baranya, im Murgebiet und in

\footnotetext{
57 Mühl Henrik országgyűlési képviselő Tolna vármegye alispánjának, Bonyhád, 1939. november 17. [Der Parlamentsabgeordnete Henrik Mühl an den Vizegespan des Komitats Tolna, Bonyhád, 17. November 1939] - MNL TML IV 404b, Tolna vármegye alispánjának iratai, 1670/1940; Völgységi járás főszolgabírája Tolna vármegye alispánjának, Bonyhád, 1940. január 30. [Der Oberstuhlrichter des Kreises Völgység an den Vizegespan des Komitats Tolna, Bonyhád, 30. Januar 1940] - MNL TML IV 404b, Tolna vármegye alispánjának iratai, 1670/1940.

58 BArch R 1501/3333, S. 43, 62.

${ }^{59}$ Volksbund panaszjelentése a Magyar Kir. Miniszterelnökségnek, 878. sz., 1941. április [Klagebericht des Volksbundes an das Königl. Ung. Ministerpräsidentenamt, Nr. 878, April 1941] - MNL BML IV 401a, Baranya vármegye főispánja bizalmas iratai, 297/1941; Baranya vármegye főispánja a m. kir. miniszterelnöknek, Pécs, 1941. augusztus 22. [Der Obergespan des Komitats Baranya an den königl. ung. Ministerpräsidenten, Pécs, 22. August 1941] - MNL BML IV 401a, Baranya vármegye főispánjának bizalmas iratai, 522/1941; Pécsváradi járás főszolgabírája Baranya vármegye föispánjának, Pécsvárad, 1941. augusztus 20. [Der Oberstuhlrichter des Kreises Pécsvárad an den Obergespan des Komitats Baranya, Pécsvárad, 20. August 1941] - MNL BML IV 401a, Baranya vármegye főispánjának bizalmas iratai, $522 / 1941$
} 
Westungarn, wo diese schon fast als patriotische Handlungen galten. ${ }^{60}$

Aus dem Material des Komitatsarchivs Baranya geht hervor, dass die Prozesse wegen Schmähung der Nation sich zur Zeit der Gründung des Volksbundes stark vermehrten, was offensichtlich zeigt, dass die nationalen Interessen, die zur Genehmigung des Volksbundes geführt hatten, nicht bis zur Ebene der ungarischen Verwaltungsorgane durchgedrungen waren. Da man versuchte, die Organisationsarbeit des Volksbundes zu behindern, wuchs selbstverständlich auch der Radikalismus der deutschen Bevölkerung.

All diese Fälle beeinträchtigten das ziemlich positiven Selbstbild der ungarischen Behörden nicht und schmälerten auch den realitätsfremden, an sich selbst wahrgenommenen Mangel, dass ihre „zuvorkommende“ Einstellung eher mit einer negativen Auswirkung einherging, die der Volksbund ihrer Ansicht nach missbrauchte, indem er die Behörden zum Gespött machte und die Bevölkerung bewusst gegen sie aufbringen wollte. ${ }^{61}$ Dies entsprach insofern der Wahrheit, dass die Ortsgruppen in ihren Aktivitäten nicht behindert wurden, selbst wenn ihre offizielle Gründung noch nicht genehmigt war, außerdem war zu beobachten, dass die frühere strenge Regelung, laut der nur Vereinsmitglieder an den Veranstaltungen teilnehmen durften, bedeutend nachließ. Die lokalen Behörden tolerierten, dass über die Mitgliedschaft hinaus weit mehr Personen an den Gründungssitzungen des Volksbundes teilnahmen, bis es in Szebény im Komitat Baranya schließlich zu einem Zwischenfall kam und die Gründungssitzung aufgrund des feindseligen Verhaltens und Handgreiflichkeiten vonseiten der ungarischen Bevölkerung unterblieb. Der Obergespan des Komitats Baranya signalisierte dem Innenminister erst danach, dass es beim Volksbund ein allgemeines Phänomen sei, die rechtlichen Vereinsregeln nicht zu befolgen, laut denen nur Mitglieder an den Veranstaltungen teilnehmen dürften. Stattdessen halte man eher Volksversammlungen ab, zuweilen riesige Massenkundgebungen, bei denen am Ende zwar in der Tat eine Ortsgruppe gegründet würde, doch zuweilen auch das unterbliebe. Es sei deutlich zu sehen, dass diese Veranstaltungen das Ziel verfolgten, jenen Einwohnern zu drohen, die sich im Hinblick auf einen Beitritt unsicher zeigten, und Überzeugungsarbeit zu leisten, daher mobilisiere man Massen aus benachbarten Ortschaften. Auch die Gendarmerie empfahl dem Obergespan, die aus den Nachbargemeinden eintreffenden „Schwaben“ fernzuhalten, vor allem, da die VolksbundFührer in Szebény schon das zweite Mal eine Menschenmenge von 2000 Personen als Demonstration ihrer Stärke aufmarschieren lassen wollten. ${ }^{62}$

Das Versammlungsrecht war durch die Verordnung Nr. 8120/1938 M.E. sowie durch die Vollzugsanweisung Nr. 15.0000/1941 B.M. geregelt. Diese untersagten das Abhalten von Volksversammlungen und Aufmärschen mit politischem Charakter sowie anderer politischer Zusammenkünfte, jede andere Art von Versammlung war an eine Genehmigung durch die

\footnotetext{
${ }^{60}$ Meldungen aus dem Reich, Nr. 224, 30. September 1941, Volkstum - BArch, R 43II/1503.

${ }^{61}$ Baranya vármegye főispánja a magyar királyi belügyminiszternek, Pécs, 1940. október 21. [Der Obergespan des Komitats Baranya an den königlich ungarischen Innenminister, Pécs, 21. Oktober 1940] - MNL BML IV 401a, Baranya vármegye főispánjának bizalmas iratai, 549/1940.

${ }^{62}$ Baranya vármegye főispánja a magyar királyi belügyminiszternek, Pécs, 1941. február 13. [Der Obergespan des Komitats Baranya an den königlich ungarischen Innenminister, Pécs, 13. Februar 1941] - MNL BML IV 401a, Baranya vármegye főispánjának bizalmas iratai, 90/1941; M. kir. pécsi IV. csendőrkerületi parancsnokság a főispánnak, Pécs, 1941. február 10. [Der königl. ung. IV. Gendarmeriebezirk Pécs an den Obergespan, Pécs, 10. Februar 1941] - MNL BML IV 401a, Baranya vármegye főispánjának bizalmas iratai, 103/1941.
} 
Polizeibehörde gebunden. Die gesellschaftlichen Vereine sowie die gemäß einem eigenen Gesetz gegründeten Vereinigungen und die politischen Parteien durften also nur Zusammenkünfte abhalten, die nicht politischer Art waren. Ferner war es diesen Organisationen erlaubt, in ihren eigenen Räumlichkeiten (Wohnhäusern oder umzäunten Höfen) geschlossene Veranstaltungen zu organisieren, an denen die Führerschaft und die vor Ort wohnenden Mitglieder teilnehmen konnten $^{63}$ - das heißt, in der konkreten Praxis machte man mehr Zugeständnisse. Ab 1942 wurden zunehmend öfter Veranstaltungen im öffentlichen Raum durchgeführt, weil die Teilnehmer nicht ausreichend Platz im Vereinsheim oder auf dessen Hof hatten. Häufig kam nämlich eine Menschenmenge von bis zu mehreren Tausend Personen zusammen, was die örtlichen Behörden zwar beanstandeten, doch kümmerte sich der Volksbund nicht um die eventuellen Anzeigen und bezahlte die Bußgelder meist einfach. Ab dem Frühjahr 1943 versuchte man anscheinend, die geltende Verordnung wieder stärker durchzusetzen, was vermutlich eine Folge der Kriegswende war. Kritisiert wurde dieses Vorgehen vor allem von der Volksbund-Führerschaft in Südtransdanubien. ${ }^{64}$

Dieser Verschärfung ging ein Aufruf des Innenministers voraus, laut dem die Heimabende des Volksbundes zwar nicht verpflichtend angemeldet werden mussten, jedoch ausschließlich in den offiziellen Vereinsräumen und nur unter Teilnahme der Mitglieder der Ortsgruppe stattfinden durften, Veranstaltungen offizieller Art waren untersagt und konnten nicht mit Musik- oder Tanzveranstaltungen verknüpft werden, da für diese eine gesonderte polizeiliche Genehmigung notwendig war. Die Heimabende konnten demnach nur einfache Besprechungen und unterhaltsame Treffen der Ortsgruppenmitglieder ohne ein öffentlich angekündigtes Programm sein. Die Polizeibehörden hatten die Pflicht, die Zusammenkünfte zu überwachen, doch waren Behelligungen zu vermeiden. ${ }^{65}$

Gerade dem akkuraten Vorgehen der Behörden ist es zu verdanken, das heute unzählige Quellen zur Verfügung stehen, denn der Volksbund und die DJ kamen ihrer Verpflichtung grundlegend nach und meldeten ihre Veranstaltungen in der Regel an. Der Kontrollmechanismus lässt ein gut ausgereiftes System erahnen, das mit der Anmeldepflicht bei den Oberstuhlrichtern begann und zum Ergebnis eine Kenntnisnahme oder Ablehnung hatte. Im ersteren Fall setzte sich sogleich jener Mechanismus in Gang, der eine sichtbare (durch Polizei, Gendarmerie, den Oberstuhlrichter oder einer unterstellten Person durchgeführte) oder unsichtbare (durch andere Informanten versehene) Überwachung der Volksbund-Veranstaltung ermöglichte. Die Eindrücke aus diesen Überwachungen und die erhaltenen Informationen fanden dann in den Berichten der

\footnotetext{
${ }^{63}$ Baranya vármegye főispánja a Magyarországi Németek Szövetsége alsódunántúli vezetőségének, Pécs, 1943. április 30. [Der Obergespan des Komitats Baranya an die Führung des südtransdanubischen Volksbundes der Deutschen in Ungarn, Pécs, 30. April 1943] - MNL BML IV 401a, Baranya vármegye főispánjának bizalmas iratai, 199/1943.

${ }^{64}$ Baranya vármegye főispánja a m. kir. belügyminiszternek, Pécs, 1942. május 13. [Der Obergespan des Komitats Baranya an den königl. ung. Innenminister, Pécs, 13. Mai 1942] - MNL BML IV 401a, Baranya vármegye főispánjának bizalmas iratai, 384/1942; Magyarországi Németek Szövetsége alsó-dunántúli vezetősége Baranya vármegye főispánjának, Pécs, 1943. március 30. [Die Führung des südtransdanubischen Volksbundes der Deutschen in Ungarn an den Obergespan des Komitats Baranya, Pécs, 30. März 1943] - MNL BML IV 401a, Baranya vármegye föispánjának bizalmas iratai, 199/1943.

${ }^{6}$ M. kir. belügyminiszter az alispánoknak és a budapesti és vidéki rendőrkapitányoknak, Budapest, 1943. március 8. [Der königl. ung. Innenminister an die Vizegespane und die Polizeipräsidenten Budapests und der Provinz, Budapest, 8. März 1943] - MNL BML IV 401a, Baranya vármegye főispánjának bizalmas iratai, 155/1943.
} 
Oberstuhlrichter Niederschlag, die den Obergespanen zugesandt wurden. Diese wiederum unterbreiteten ihre wichtigsten Gesichtspunkte samt den Berichten aller Kreise des Komitats dem Innenminister, der sich ein umfassendes Bild von der Lage im Land machte, das er an das Ministerpräsidentenamt weiterleitete.

Der Obernotar der Gemeinde Piliscsaba bewertete den Kampf gegen den Volksbund trotz aller Möglichkeiten, über die die ungarische Verwaltung verfügte, so, dass die Behörden praktisch nackt dastünden, nichts in der Hand hätten und die Anzeigen keine Wirkung zeigten. Seiner Ansicht nach war es diesem Umstand zu verdanken, dass sich die Jugend des Volksbundes als außergesetzlich betrachtete und "mit ihrem unpatriotischen Benehmen und Verbalten" provozierte. Es zeigte sich, dass der Einfluss des Volksbundes auf die Jugend vor allem dort recht erfolgreich und gerade deswegen für die Behörden besorgniserregend war, wo auch Lehrer in der Bewegung aktiv waren. So wie beispielsweise gerade in Piliscsaba oder Pilisszentiván. ${ }^{66}$

Zur zweiten Hälfte des Jahres 1941 eskalierte die Situation in den einzelnen Dörfern, wo die Volksbund-Anhänger mal mit den Behörden, mal mit Deutschen, die keine Anhänger der Organisation waren, Ungarn oder Kroaten in Konflikt gerieten. Bei einem Ball in Nagykozár im Komitat Baranya kam es zu einer Schlägerei zwischen deutschen und kroatischen Jugendlichen, bei der die Deutschen den Kroaten mit der Vergeltung Hitlers und Deutschlands drohten. Danach versöhnten sich die beiden Parteien jedoch. ${ }^{67}$ Es war mittlerweile sehr schwer, die Situation zu handhaben. Der Obergespan des Komitats Baranya mahnte die Oberstuhlrichter regelmäßig, unangemessene Maßnahmen vonseiten der Behörden einzustellen, Straftaten jedoch zu verfolgen, um die Stimmung einigermaßen zu beruhigen. Während der Obergespan beide Seiten in der aktuellen Situation für schuldig hielt, betrachtete er das Wirken des Volksbundes dennoch als den Ursprung der Probleme, die Ohnmacht der Behörden hingegen führte er darauf zurück, dass sie im Gegensatz zum UDV dem Volksbund gegenüber, dessen Wirken zu der Zeit bereits ein zwischenstaatlicher Vertrag garantierte, nicht wirkungsvoll auftreten konnten und unfähig waren, das Vorgehen der einzelnen Ortsgruppen einzuschränken. ${ }^{68}$

Eine Verbitterung war auch beim Volksbund spürbar, Basch bat das Ministerpräsidentenamt persönlich darum, die Gendarmerie anzuweisen, energisch gegen die Angriffe auf den Volksbund vorzugehen und diese zu ahnden. Der Obergespan des Komitats Baranya forderte den Volksbund ebenfalls auf, bei etwaigen Vorfällen Klage zu erheben, merkte jedoch an, dass diese jeweils begründet sein sollten. Gleichzeitig bat er um eine schnelle Reaktion, damit die Sachverhalte aufgedeckt werden konnten, im Interesse des Landes versprach er, wohlwollend vorzugehen, um die Spannungen abzubauen. Er bat die Parteien, eventuelle Beschwerden nicht als persönliche

\footnotetext{
${ }^{66}$ Piliscsaba vezetőjegyzője a Szentendrei járás főszolgabírájának, Piliscsaba, 1941. február 25. [Der Obernotar von Piliscsaba an den Oberstuhlrichter des Kreises Szentendre, Piliscsaba, 25. Februar 1941] - MNL PML IV 401a, PestPilis-Solt-Kiskun vármegye főispánjának bizalmas iratai, 8/1941; Buda-környéki járás főszolgabírája a főispánnak, Budapest, 1941. január 10. [Der Oberstuhlrichter des Kreises Buda-környék an den Obergespan, Budapest, 10. Januar 1941] - MNL PML IV 401. a, Pest-Pilis-Solt-Kiskun vármegye főispánjának bizalmas iratai, 13/1940.

${ }^{67}$ Ebd.

${ }^{68}$ Vgl. Baranya vármegye főispánja a magyar kir. belügyminiszternek, Pécs, 1941. július 4. [Der Obergespan des Komitats Baranya an den königl. ungarischen Innenminister, Pécs, 4. Juli 1941] - MNL BML IV 401a, Baranya vármegye főispánja bizalmas iratai, 393/1941; Baranya vármegye főispánja a magyar kir. belügyminiszternek, Pécs, 1941. június 10. [Der Obergespan des Komitats Baranya an den königl. ungarischen Innenminister, Pécs, 10. Juni 1941] - MNL BML IV 401a, Baranya vármegye főispánja bizalmas iratai, 331/1941.
} 
Beleidigung zu werten, sondern zu versuchen, sachlich zu bleiben, den Behörden gegenüber Höflichkeit zu bewahren. Dass die Behörden immer wieder davon berichteten, dass Volksbundund DJ-Führer in Gemeinden erschienen seien, um die Gemüter zu beschwichtigen, zeigte einen Funken gegenseitigen Entgegenkommens. Das Innenministerium meinte zu wissen, dass man die Jugendlichen im Januar 1941 mit jener Aufforderung, sich zurückhaltend zu benehmen, das Selbstwertgefühl der Ungarn nicht zu verletzen und keine Forderungen zu stellen, losgeschickt hatte, neue Mitglieder anzuwerben. ${ }^{69}$

Gegenstand der Beanstandungen war vonseiten der Deutschen vor allem das übereifrige Verhalten der Gendarmerie, die Bemerkungen der Levente-Ausbilder, mit denen sie das Selbstwertgefühl der Mitglieder deutscher Nationalität verletzten, der besonders strenge Umgang mit den Levente deutscher Nationalität, die strengeren Strafen bei den polizeilichen strafgerichtlichen Urteilen erster Instanz, die hohe Zahl infamer Anzeigen in von Deutschen bewohnten Gebieten und die massenhaften Behelligungen als Folge dessen. Vermutlich war diese Wahrnehmung berechtigt, da die Behörden, die dem Volksbund ohnehin keine Sympathie entgegenbrachten, bei Angriffen auf die Organisation offensichtlich sehr viel nachsichtiger waren. Zur Mobilisierung war auf beiden Seiten eine gewisse Polarisierung notwendig gewesen, die danach nicht mehr im Zaum zu halten war. Laut dem Ministerpräsidentenamt entbehrten jedoch 20 Prozent der Beschwerden jeglicher Grundlage und 40 Prozent beruhten auf Missverständnissen oder auf einer übertriebenen Empfindlichkeit. Die Untersuchung der zweifelhaften Fälle aber beruhigte die deutsche Bevölkerung, was auch die Führer des Volksbundes anerkannten. ${ }^{70}$

1941 konstatierte man auch im Reich, dass die Zahl der gewalttätigen Taten gegen Mitglieder des Volksbundes von Tag zu Tag zunahmen, der Volksbund meldete dem Ministerpräsidentenamt angeblich wöchentlich hundert Fälle. Besonders empörte man sich über die Hetze durch den Klerus, wenn beispielsweise Pfarrer Kinder deswegen schlugen, weil sie Veranstaltungen des Volksbundes besuchten. ${ }^{71}$

Im September des Jahres 1941 vertrat bereits auch der Obergespan des Komitats Baranya selbst die Ansicht, dass die Mitglieder des Volksbundes reihenweise Straftaten begingen, die im Hinblick auf das ungarische Nationalgefühl stark zu kritisieren seien. Schuld daran waren seiner Meinung nach die Volksbund-Führer, die dazu anstiften würden - während er andere Male gerade den mäßigenden Einfluss der Führer hervorhob -, was er zwar nicht beweisen konnte, doch war er sich sicher, dass dies ein Ergebnis der Gesinnung sei, die in der Bewegung vorherrschte. ${ }^{72} \mathrm{Im}$ Januar 1942 artete die Beurteilung vonseiten der Behörden derart aus, dass man behauptete, im

\footnotetext{
${ }^{69}$ Basch Balla Pál miniszterelnökségi miniszteri tanácsosnak, Budapest, 1941. június 20. [Basch an den Ministerialrat des Ministerpräsidentenamtes Pál Balla, Budapest, 20. Juni 1941] - MNL BML IV 401a, Baranya vármegye főispánja bizalmas iratai, 398/1941; Baranya vármegye főispánja Mühl Henrik országgyűlési képviselőnek, Pécs, 1942. január 7. [Der Obergespan des Komitats Baranya an den Parlamentsabgeordneten Henrik Mühl, Pécs, 7. Januar 1942] - MNL BML IV 401a, Baranya vármegye főispánjának bizalmas iratai, 756/1941; Nemzetiségi és ezzel kapcsolatos külpolitikai összesítő, 2164. sz. B. Kt. 1941, Budapest, 1941. január 31. [Zusammenfassung zu den Nationalitäten und die diesbezügliche Außenpolitik, Nr. 2164 B.kt. 1941, Budapest, 31. Januar 1941] - MNL OL K 149, K 149-1941-651/9.

${ }^{70}$ A magyarországi német kisebbség helyzetképe, 1940. május 11. [Die Situation der deutschen Minderheit in Ungarn, 11. Mai 1940] - MNL OL K 28, 95. cs., K 28-194-M.E.-1940-C-17502.

${ }^{71}$ Meldungen aus dem Reich, Nr. 182, 28. April 1941, Volkstum - BArch, R 43II/1503.

72 Baranya vármegye főispánja a m. kir. belügyminiszternek, Pécs, 1941. szeptember 29. [Der Obergespan des Komitats Baranya an den königl. ung. Innenminister, Pécs, 29. September 1941] - MNL BML IV 401a, Baranya vármegye föispánjának bizalmas iratai, 589/1941.
} 
Volksbund gäbe es geheime Anweisungen durch die Führungskräfte, beabsichtigt Zusammenstöße $\mathrm{zu}$ provozieren, der Obergespan versuchte, diesen präventiv durch ständige Polizei- und Gendarmeriepatrouillen zuvorzukommen. ${ }^{73}$

Ferenc Balázs, Volksschullehrer und Inspektor des Komitats Baranya, der mit der Kontrolle der Deutschen Jugend in der Schwäbischen Türkei beauftragt wurde, kam im Laufe der Überwachung der DJ zu der Überzeugung, dass die Behörden die Problematik der Jugendorganisation im Großen und Ganzen mit der entsprechenden Objektivität behandelten, doch formulierte er zuweilen auch ihnen gegenüber Kritik. Als schwerwiegender beurteilte er die Situation jedoch im Fall der Lehrer und Geistlichen in den einzelnen Gemeinden, die der Angelegenheit der DJ in vielen Fällen vollkommen gleichgültig und ignorant gegenüberstanden, deren Satzung und Arbeit nicht kannten und die Ausschweifungen, zu denen es in der Anfangszeit der deutschen Bewegung gekommen war, seitdem nicht aufarbeiten konnten oder wollten. ${ }^{74}$

Ferenc Balázs vertrat die Ansicht, dass eine Annäherung der Parteien unerlässlich war, als Zielsetzung für ihr Zusammenleben nannte er die Wiederherstellung des gegenseitigen Vertrauens. „Ich sehe es jedoch so, dass es noch viel Zeit und eine bereitwilligere Anpassung von beiden Seiten benötigt, bis dieser Zustand allgemein erreichbar wird. Den Anzeichen nach ist eine umfassendere Integration der deutschsprachigen Bevölkerung und deren Jugend in das Leben der ungarischen Nation ₹u beobacbten, dennoch wäre es verfrübt, daraus bereits langfristig Schlüsse zu ziehen. Trotzdem ist es meiner bescheidenen Ansicht nach die Pflicht der lokalen Führungskräfte und aller zuständigen Personen im ungarischen Leben, die psychologischen Gegebenheiten der Situation in Betracht zu ziehen, zweckmäßig zu nutzen und dabei behilflich zu sein, in dieser Atmosphäre die Grundlagen für eine auf gegenseitigem Verständnis und friedlichem Zusammenleben basierenden schöneren Zukunft

\footnotetext{
${ }^{73}$ Baranya vármegye főispánja a m. kir. belügyminiszternek, Pécs, 1942. január 3. [Der Obergespan des Komitats Baranya an den königl. ung. Innenminister, Pécs, 3. Januar 1942] - MNL BML IV 401a, Baranya vármegye főispánjának bizalmas iratai, 65/1942.

${ }^{74}$ Balázs Ferenc, a V.K.M. VI. ü. o. előadója a m. kir. vallás és közoktatási miniszternek, Pécs, 1943. évi november hó 23. [Ferenc Balázs, Referent der Sachabteilung VI des Ministeriums für Kultus und Unterricht, an den königl. ung. Minister für Kultus und Unterricht, Pécs, 23. November 1943] - MNL BML IV 401a, Baranya vármegye főispánjának bizalmas iratai, 644/1943; Balázs Ferenc, a V.K.M. VI. ü. o. előadója a m. kir. vallás és közoktatási miniszternek, Pécs, 1943. évi november hó 30. [Ferenc Balázs, Referent der Sachabteilung VI des Ministeriums für Kultus und Unterricht, an den königl. ung. Minister für Kultus und Unterricht, Pécs, 30. November 1943] - MNL BML IV 401a, Baranya vármegye föispánjának bizalmas iratai, 651/1943; Balázs Ferenc, a V.K.M. VI. ü. o. előadója a m. kir. vallás és közoktatási miniszternek, Pécs, 1943. évi december hó 23. [Ferenc Balázs, Referent der Sachabteilung VI des Ministeriums für Kultus und Unterricht, an den königl. ung. Minister für Kultus und Unterricht, Pécs, 23. Dezember 1943] - MNL BML IV 401a, Baranya vármegye főispánjának bizalmas iratai, 689/1943; Balázs Ferenc, a V.K.M. VI. ü. o. előadója a m. kir. vallás és közoktatási miniszternek, Pécs, 1943. évi december hó 31. [Ferenc Balázs, Referent der Sachabteilung VI des Ministeriums für Kultus und Unterricht, an den königl. ung. Minister für Kultus und Unterricht, Pécs, 31. Dezember 1943] - MNL BML IV 401a, Baranya vármegye főispánjának bizalmas iratai, 5/1945; Balázs Ferenc, a V.K.M. VI. ü. o. előadója a m. kir. vallás és közoktatási miniszternek, Pécs, 1944. évi február hó 22. [Ferenc Balázs, Referent der Sachabteilung VI des Ministeriums für Kultus und Unterricht, an den königl. ung. Minister für Kultus und Unterricht, Pécs, 22. Februar 1944] - MNL BML IV 401a, Baranya vármegye főispánjának bizalmas iratai, 136/1944; Balázs Ferenc, a V.K.M. VI. ü. o. előadója a m. kir. vallás és közoktatási miniszternek, Pécs, 1944. évi június hó 7. [Ferenc Balázs, Referent der Sachabteilung VI des Ministeriums für Kultus und Unterricht, an den königl. ung. Minister für Kultus und Unterricht, Pécs, 7. Juni 1944] - MNL BML IV 401a, Baranya vármegye főispánjának bizalmas iratai, 406/1944; Balázs Ferenc, a V.K.M. VI. ü. o. előadója a m. kir. vallás és közoktatási miniszternek, Pécs, 1944. évi június hó 15. [Ferenc Balázs, Referent der Sachabteilung VI des Ministeriums für Kultus und Unterricht, an den königl. ung. Minister für Kultus und Unterricht, Pécs, 15. Juni 1944] - MNL BML IV 401a, Baranya vármegye főispánjának bizalmas iratai, 406/1944; Balázs Ferenc, a V.K.M. VI. ü. o. előadója a m. kir. vallás és közoktatási miniszternek, Pécs, 1944. évi június hó 16. [Ferenc Balázs, Referent der Sachabteilung VI des Ministeriums für Kultus und Unterricht, an den königl. ung. Minister für Kultus und Unterricht, Pécs, 16. Juni 1944] - MNL BML IV 401a, Baranya vármegye főispánjának bizalmas iratai, 406/1944.
} 
zu legen. ${ }^{\text {"5 }}$

Der Volksbund und die DJ standen die gesamte Zeit über im Kreuzfeuer der ungarischen Behörden. Diese gesteigerte und angespannte Konzentration auf die Organisationen, ihre strenge Überwachung und Beobachtung bedeuteten für beide Seiten eine nervliche Belastung, die des Öfteren zu verbalen und physischen Konflikten führte. Radikale Stimmen waren mancherorts schon vor dem Volksgruppenabkommen zu hören gewesen. So hieß es beispielsweise, dass die Jugend in Kakasd einen ,gewaltsamsten Terror" an den Tag legte, Transdanubien drohte mit deutscher Besetzung und „im Allgemeinen war es die schwächste Prophezeiung der ungarischen Dorfintelligen₹, dass man sie mit der Peitsche ganz bis zum Schwarzen Meer treibt". ${ }^{76} \mathrm{Zu}$ Beginn der vierziger Jahre wurden die Behörden meist verbal attackiert, ab 1941 wurde die lokale Intelligenz - Pfarrer und Beamten auf Veranstaltungen immer häufiger in Reden an den Pranger gestellt.

In physische Aggression schlugen diese Angriffe vermutlich in dem Moment um, als die Emotionen ihren Höhepunkt erreichten. Es wurde eine ganze Zahl von Fällen aufgezeichnet, bei denen die Jugendlichen diese Atrozitäten, in die sich die Erwachsenen mal aufpeitschend, mal beschwichtigend einmischten, durch ihre eigene Unüberlegtheit und Hitzigkeit auf sich nahmen. Laut der Beurteilung des lokalen Verwaltungsapparats zeigte sich in einzelnen Ortschaften, wie etwa in Majs, ein ,, regelrechter revolutionärer Zustand “77 andere Male sprach der Volksbund von Terror.

Insbesondere bei der Gendarmerie kamen körperliche Misshandlungen in Form von Schlägen, Ohrfeigen usw. des Öfteren vor. Mancherorts gab es sogar Beispiele, die noch demütigender waren: So befahl man den DJ-Mitgliedern in Sajkaszentiván sich als Strafe gegenseitig zu ohrfeigen, als den Gendarmen aber auch das nicht genügte, zeigten sie selbst, wie man das ordentlich machen musste. ${ }^{78}$

Die in vielerlei Hinsicht zugespitzte Situation artete häufig in Schlägereien oder Messerstechereien aus, so wie beispielsweise in Hercegtöttös, wo die Volksbund-Jugend auf staatstreue Deutsche losging, die sich in der Wirtschaft amüsierten. In Újpetre verpasste man den patriotisch gesinnten Jugendlichen einfach Ohrfeigen. Die Gendarmerie meinte darin bereits eine neue, im Vergleich zu früher aggressivere Taktik zu erkennen, ihrer Ansicht nach wollte der Volksbund, wenn es keine Zeugen gab, mit physischer Aggression erzwingen, dass die eher zurückhaltende Bevölkerung in die Organisation eintrat. In Németbóly gingen die Schüler der staatlichen Schule und jener der Bürgerschule des Volksbundes regelmäßig aufeinander los, wovon der Oberstuhlrichter allerdings keine Kenntnis hatte! $!^{79}$

\footnotetext{
${ }^{75}$ Balázs Ferenc, a V.K.M. VI. ü. o. előadója a m. kir. vallás és közoktatási miniszternek, Pécs, 1943. évi november hó 23. [Ferenc Balázs, Referent der Sachabteilung VI des Ministeriums für Kultus und Unterricht, an den königl. ung. Minister für Kultus und Unterricht, 23. November 1943] - MNL BML IV 401a, Baranya vármegye fóispánjának bizalmas iratai, 644/1943.

${ }^{76}$ Másolat a 9143. VII. res sz. kiadványhoz [Abschrift zur Publikation Nr. 9143. VII. res] - MNL OL K 63, 196. cs, K63-1940-21/7.

77 Zum Beispiel wollten die Jugendlichen in Nagynyárád den Kreisnotar mit faulen Eiern bombardieren, was schließlich von einem Führer des Volksbundes verhindert wurde. - Majsi körjegyző panasza a mohácsi járás főszolgabírójának, Majs, 1942. május 4. [Klage des Kreisnotars von Majs an den Oberstuhlrichter des Kreises Mohács, Majs, 4. Mai 1942] - MNL BML IV 410a, Baranya vármegye alispánjának elnöki iratai, 53. doboz, 1942.

78 Volksdeutsche Mittelstelle an das AA, Berlin, 31. März 1943 - PAAA, R 100396.

${ }^{79}$ Magyar Kir. Pécsi IV. Csendőrkerület Baranya vármegye főispánjának, Pécs, 1941. június 24. [Der königl. ung. IV. Gendarmeriebezirk Pécs an den Obergespan des Komitats Baranya, Pécs, 24. Juni 1941] - MNL BML IV 401a, Baranya vármegye főispánja bizalmas iratai, 374/1941; Magyar Kir. Pécsi IV. Csendőrkerület Baranya vármegye főispánjának,
} 
In Újpetre radikalisierte sich die Volksbund-Jugend ganz besonders, immer wieder insultierten die Jugendlichen die „patriotische“ Bevölkerung, beschmierten Häuser und Zäune, montierten Tore ab, verprügelten Menschen, rissen das Gemüse aus den Beeten. In Vokány ließen deutsche Jugendliche 723 Liter Wein in einem Keller auslaufen. In Baranyabán schlugen sie mit Keulen auf „patriotische“ Einwohner ein, manche trugen sogar Kopfverletzungen davon. Die Führung des Volksbundes war nicht in der Lage, diesen Ausschreitungen Einhalt zu gebieten. ${ }^{80}$

Sogar 1942 standen Atrozitäten dieser Art auf der Tagesordnung: Es wurden Reben ausgerissen, Fenster eingeworfen usw. In der Umgebung von Majs war angeblich der Ausgangspunkt für die Angriffe der Bauernknecht Márton Kriszt. ${ }^{81}$ Das heißt, ein einziger „fauler Apfel“" konnte in der ohnehin angespannten Situation bereits großen Schaden anrichten.

Bei den Jugendlichen kam es gerade aufgrund ihres Alters sehr häufig zu Trotzreaktionen und zuweilen in Devianz umschlagende Handlungen. Die Generationsunterschiede konnten also auch in diesem Bereich zu Problemen führen. Streitereien und Verspottungen wurden zum Alltag, die Jugendlichen gingen entsprechend den jeweiligen Kräfteverhältnissen aufeinander los. Und dabei stellten auch die Mädchen keine Ausnahme dar. Dass die Älteren zur Mäßigung mahnten, wurde von der jüngeren Generation nicht immer akzeptiert, da die Jugendlichen ihren eigenen radikaleren Weg verfolgen wollten, und das häufig sogar nach $1942 .{ }^{82}$

1943 ließen die Konflikte etwas nach: Einerseits hatte man sich an die neue Ordnung seit der Besetzung des Landes durch die Deutschen gewöhnt, andererseits beruhigten auch der Eintritt der Wortführer in die SS und die veränderte Stimmung nach Stalingrad die Situation.

Die Hypersensitivität der Behörden in den „pangermanischen“ Fällen wird noch offensichtlicher, wenn man einige Kirchenbücher studiert. John C. Swanson machte die Beobachtung, dass die Pfarrer in ihren Einträgen vor 1930 nicht die Ethnizität als Bezugsgrundlage betrachteten, sondern eher die gesellschaftliche Schichtung. Daher nahmen sie keine ethnischen Probleme wahr und wurden somit auch auf das Phänomen des „Pangermanismus“ nicht aufmerksam. In Majs stand der erste Eintrag dieser Art im Zusammenhang mit dem UDV und stammte aus dem Jahr 1934, wobei hier seit 1927 bereits eine Ortsgruppe existierte. ${ }^{83}$

Pécs, 1941. december 29. [Der königl. ung. IV. Gendarmeriebezirk Pécs an den Obergespan, Pécs, 29. Dezember 1941], Magyar Kir. Pécsi IV. Csendôrkerület Baranya vármegye föispánjának, Pécs, 1941. december 30. [Der königl. ung. IV. Gendarmeriebezirk Pécs an den Obergespan, Pécs, 30. Dezember 1941], Mohácsi járás főszolgabírája Baranya vármegye főispánjának, Mohács, 1942. január 26. [Der Oberstuhlrichter des Kreises Mohács an den Obergespan des Komitats Baranya, Mohács, 26. Januar 1942] - MNL BML IV 401a, Baranya vármegye főispánjának bizalmas iratai, $816 / 1941$.

${ }^{80}$ Baranya vármegye főispánja a magyar kir. belügyminiszternek, Pécs, 1942. február 20. [Der Obergespan des Komitats Baranya an den königl. ung. Innenminister, Pécs, 20. Februar 1942] - MNL BML IV 401a, Baranya vármegye főispánjának bizalmas iratai, 147/1942; Villányi járás főszolgabírája Baranya vármegye főispánjának, Villány, 1942. június 4. [Der Oberstuhlrichter des Kreises Villány an den Obergespan des Komitats Baranya, Villány, 4. Juni 1942] MNL BML IV 401a, Baranya vármegye főispánjának bizalmas iratai, 491/1942.

81 Mohácsi járás főszolgabírája Baranya vármegye főispánjának, Mohács, 1942. július 9. [Der Oberstuhlrichter des Kreises Mohács an den Obergespan des Komitats Baranya, Mohács, 9. Juli 1942] - MNL BML IV 401a, Baranya vármegye főispánjának bizalmas iratai, 553/1942. ld további eseteket: 595/1942.

${ }^{82}$ Vgl. Pécsváradi járás főszolgabírája Baranya vármegye főispánjának, Pécsvárad, 1943. április 6. [Der Oberstuhlrichter des Kreises Pécsvárad an den Obergespan des Komitats Baranya, Pécsvárad, 6. April 1943] - MNL BML IV 410a, Baranya vármegye alispánjának elnöki iratai, 53. doboz, 1943.

${ }^{83}$ Die Kirchenbücher von Majs und Máriakéménd zitiert SWANSON, 228-231; FLACH, Ortsgruppengründungen des Ungarländischen Deutschen Volksbildungsvereins 10. 
In dem überwiegenden Teil der im Bundesarchiv-Lastenausgleichsarchiv aufbewahrten Gemeindeschicksalsberichten (Ostdok) erinnerten sich die Menschen so, dass die Arbeit des Volksbundes nicht behindert worden sei. Nur bei einem geringeren Teil erschienen der Lehrer, der Gendarm, die ungarische Bevölkerung, der KALOT oder die Einwohner, die keine VolksbundMitglieder waren, als Konfliktquelle, in mehreren Fällen berichteten sie nur von kleineren Konflikten oder Auseinandersetzungen einiger Wortführer. Zu beachten ist selbstverständlich, dass sich die Personen in ihren Berichten häufig nicht genauso zurückerinnern, was einfach die Unterschiedlichkeit der persönlichen Erinnerungen zeigt, bei einer größeren Gemeinde gegebenenfalls aber auch die lokalen Abweichungen innerhalb der Ortschaft. ${ }^{84}$

All dies beleuchtet zwar, dass die Konfliktsituationen in der Geschichte des UDV, des Volksbundes und der DJ ein markantes Charakteristikum darstellten, jedoch kann man nicht einmal annähernd wissen, wie viele „problemfreie“ Veranstaltungen und Versammlungen es im Vergleich dazu gab, daher lohnt es auch nicht, dieses Phänomen zu überdimensionieren.

\section{Folgerungen}

Mit dem Ersten Weltkrieg ging für viele der langersehnte Traum von unabhängigem Ungarn in Erfüllung. Die Freude darüber war jedoch bald von der Auflösung des historischen Ungarn überschattet. Dies bedeutete zugleich eine neue Etappe für den ungarischen Nationalstaat, in dem sich nach 1920 auf eine volle ethnische Homogenisierung eine neue Chance bot. Diese Bestrebungen konnten jetzt nur noch durch die infolge der Grenzziehungen zur größten Minderheit gewordenen Deutschen gehindert werden, die für ihren ethnischen Bestand den Weg der Gruppenbildung und Selbstorganisation betraten. Indem dies vom internationalen Minderheitenschutz begünstigt werden sollte, versuchte Ungarn das ethnic revival der Deutschen in Ungarn in erster Linie mit bürokratischen Mitteln zu verhindern, wozu die vor 1918 angewandten Praktiken verwendet, ergänzt und weiterentwickelt wurden. Die strenge Überwachung, das Schüren der Angst vor der pangermanischen Gefahr, Hinderung der Organisationstätigkeit, die militärische Strafversetzung, die Maßnahmen der Polizei und der Gendarmerie, Schikanierungen, Anzeigen, Inhaftierungen und Gewalttaten bildeten Bestandteile eines gut funktionierenden Systems, womit die Ausübung der zugesprochenen und international garantierten Minderheitenrechte erfolgreich sabotiert werden konnte.

\section{Quellen- und Literaturverzeichnis}

Az 1920. évi népszámlálás, 1. kötet [Volkszählung 1920, Band 1]. Budapest 1923

BELLÉR Béla: Az ellenforradalmi rendszer nemzetiségi politikájának kialakulása [Die Entwicklung der Nationalitätenpolitik des konterrevolutionären Systems]. Budapest 1975

BELLÉR Béla: Az ellenforradalmi rendszer nemzetiségi politikája a válság küszöbén (1930-1931) [Die Nationalitätenpolitik des konterrevolutionären Systems an der Schwelle zur Krise (1930-1931)]. Századok

\footnotetext{
84 Siehe die Erinnerungen zum Komitat Baranya, Ostdok, 17/31, Bácska - Ostdok, 17/30 - übriges Ungarn - Ostdok, 17/32, Pest-Pilis-Solt-Kiskun - Ostdok, 17/33, Somogy - Ostdok, 17/34, Sopron környéke- Ostdok, 17/35, Tolna Ostdok, 17/36, Veszprém megye - Ostdok, 17/37.
} 
2/1977

BŐZSE Sándor: „Az egyesületi élet a polgári szabadság ...“ Somogy megye egyesületei a dualizmus korában [„Das Vereinsleben ist die bürgerliche Freiheit ...“ Die Vereine des Komitats Somogy zur Zeit des Dualismus]. Somogyi Almanach, Nummer 53, Kaposvár 1997, 17-20.

EGRY Gábor: Nemzeti védgát vagy szolíd haszonszerzés?: Az erdélyi szászok pénzintézeti rendszere és szerepe a nemzeti mozgalomban (1835-1914) [Nationaler Schutzdamm oder solider Nutzen? Das Finanzsystem der Siebenbürger Sachsen und seine Rolle in der nationalen Bewegung (1835-1914)]. Csíkszereda 2009

EILER Ferenc: Nemzeti kisebbségek és az állammal szembeni lojalitás a két világháború között. Elvek és gyakorlat az Európai Nemzetiségi Kongresszus tevékenységében 1925-1938. In: KovÁcs, Nóra (Hrsg.): Etnikai identitás, politikai lojalitás. Nemzeti és állampolgári kötődések. Budapest 2005, 204-219.

FLACH, Paul: Ortsgruppengründungen des Ungarländischen Deutschen Volksbildungsvereins (1924-1940) und des Volksbundes der Deutschen in Ungarn. Landsmannschaft der Deutschen aus Ungarn in Bayern. München 1968

FÜZES Miklós (Hrsg.): Nemzetiségi ügyek dokumentumai Baranyában 1923-1938. Pécs 2001

GOTTAS, Friedrich: Vereine, Parteien und Interessenverbände der ungarländischen Deutschen. In: RUMPLER, Helmut - UrbanitsCH, Peter (Hrsg.): Die Habsburgermonarchie 1848-1918, Band 8: Politische Öffentlichkeit und Zivilgesellschaft, 1. Teilband: Vereine, Parteien und Interessenverbände als Träger der politischen Partizipation. Wien 2006, 1205-1241.

GOTTAS, Friedrich: Die Deutschen in Ungarn. In: WANDRUSZKA, Adam - UrBANITSCH, Peter (Hrsg.): Die Habsburgermonarchie 1848-1918, Band 3, 1: Die Völker des Reiches. Wien 1980, 340-410.

HUTTERER, Claus Jürgen: Die deutsche Volksgruppe in Ungarn. In: WEBER-KELLERMANN, Ingerborg (Hrsg.): Zur Interethnik. Donauschwaben, Siebenbürger Sachsen und ihre Nachbarn. Frankfurt/M. 1978

KovÁcs Alajos: A németek helyzete Csonka-Magyarországon a statisztika megvilágításában [Die Situation der Deutschen in Rumpf-Ungarn im Spiegel der Statistik]. Budapest 1936

Móró Mária Anna: Olvasóegyletek és népkönyvtárak Baranyában 1914-ig [Lesevereine und Volksbüchereien im Komitat Baranya bis 1914]. Baranyai Helytörténetírás 1977, 169-196.

MANNOVÁ, Elena: Das Vereinswesen in Ungarn und die Revolution 1848/49 (am Beispiel von Oberungarn/Slowakei). In: FISCHER, Holger (Hrsg.): Die ungarische Revolution von 1848/49. Hamburg 1999, 57-67.

MANNOVÁ, Elena: Identitätsbildung der Deutschen in Pressburg im 19. Jahrhundert. Halbasien. Zeitschrift für deutsche Literatur und Kultur Südosteuropas 5/1995, 60-76.

MÁRAI Sándor: Bekenntnisse eines Bürgers. Berlin 2000

MÁRFi Attila: Baranya nemzetiségi egyesületei a dualizmus idején [Die Nationalitätenvereine des Komitats Baranya zur Zeit des Dualismus]. Kisebbségek együttélése 6/2004, 9-15.

METZ, Franz: Josef Angster. Das Tagebuch eines Orgelbauers. Donauschwäbische Kulturstiftung. München 2004

MNL BML = Komitatsarchiv Baranya des Ungarischen Nationalarchivs IV 401a

MNL BKML = Komitatsarchiv Bács-Kiskun des Ungarischen Nationalarchivs IV 903a

MNL PML $=$ Komitatsarchiv Pest des Ungarischen Nationalarchivs IV 401a

MNL TML $=$ Komitatsarchiv Tolna des Ungarischen Nationalarchivs IV 404b

MNL OL = Landesarchiv des Ungarischen Nationalarchivs K 149

NÉmeth G. Béla (Hrsg.): Herczeg Ferenc emlékezései [Die Erinnerungen von Ferenc Herczeg]. Budapest 1985

P. MIKLós Tamás: „Ifjúsági szerveződések évszázadai“ - gyermek- és ifjúsági szervezetek a XIX-XX. századi Magyarországon [,Jahrhunderte der Jugendorganisationen“ - Kinder- und Jugendorganisationen im Ungarn des 19.-20. Jahrhunderts]. Új Pedagógiai Szemle, November/1997.

https:/ / epa.oszk.hu/00000/00035/00010/1997-11-mk-P-Miklos-Ifjusagi.html (12. 02. 2020)

REISZ László: Egyletek a dualizmuskori Magyarországon [Vereine in Ungarn während der Dualismuszeit]. Statisztikai Szemle 66 (1988), 930-946.

SCHÖDL, Günter: Lange Abschiede: Die Südostdeutschen und ihre Vaterländer (1918-1945). In: Ders. (Hrsg.):

Deutsche Geschichte im Osten Europas. Land an der Donau. Berlin 1995, 455-530.

SCHWIND, Hedwig: Jakob Bleyer. Ein Vorkämpfer und Erwecker des ungarländischen Deutschtums. München 1960

SEBESTYÉN Éva: Szerb egyesületek és nemzetiségi politika Pest megyében a dualizmus időszakában. In: Tanulmányok Pest Megye múltjából IV. Budapest 2012, 85-96. 
SEEWANN, Gerhard: Geschichte der Deutschen in Ungarn 1-2. Marburg 2012

SOMLAI Péter Ferenc: A magyarországi németség története a Budai-hegyvidéken Budakeszi település példáján (1935 1946) [Die Geschichte der Deutschen in Ungarn im Ofner Bergland am Beispiel von Budakeszi]. Msc. Budapest 2014

SPANNEnBERGER, Norbert: Der Volksbund der Deutschen in Ungarn 1938-1944 unter Horthy und Hitler. München 2002

SPIRA, Thomas: German-Hungarian Relations and the Swabian Problem. From Károlyi to Gömbös, 1919-1936. New York 1977

SPIRA, Thomas: The German-Hungarian-Swabian Triangle 1936-1939. A Road to Discord. New York 1990 SZALAYNÉ SÁNDOR Erzsébet: A kisebbségvédelem jogi intézményrendszere a 20. században, Budapest 2003

SzITA László: Adatok a Magyarországi Németek Országos Gazdaszövetsége történetéhez (1909-1921) [Beiträge zur Geschichte des Landesbauernverbands der Ungarndeutschen (1909-1921)]. In: SOMOGYI, Éva (Hrsg.):

Polgárosodás Közép-Európában. Tanulmányok Hanák Péter 70. születésnapjára. Budapest 1991, 243-255.

TEuTSCH, Daniel - TEuTSCH, Friedrich: Geschichte der Siebenbürger Sachsen für das sächsische Volk, Band 1-4, Leipzig/Hermannstadt 1874-1926, Nachdruck: Köln 1984

TILKOVSZKY Loránt: A magyarországi német mozgalom válságának kibontakozása (1930-1932) [Die Entfaltung der Krise der ungarndeutschen Bewegung (1930-1932)]. In: Somogy megye múltjából 10. Kaposvár 1979, 403445.

WiESER, Stefan: Wir zogen aus Schwaben nach Osten. In: ScHMIED, Stefan (Hrsg.): Heimatbuch der Sathmarer Schwaben. Wangen/Allgäu 1952, 5-67. 